\title{
AS FORMAS DE PROVIMENTO DO CARGO DE DIREÇÃO DAS ESCOLAS MUNICIPAIS E OS DESAFIOS AO PNE: UMA ANÁLISE A PARTIR DA MUNIC E DA ESTADIC (2014)*
}

\author{
Márcio Alexandre Barbosa Lima ${ }^{I}$ \\ Robson dos Santos II
}

http://dx.doi.org/10.24109/9788578630669.ceppe.vla10

\section{RESUMO}

O trabalho objetiva trazer subsídios para a construção de indicadores voltados ao monitoramento da Meta 19 do Plano Nacional de Educação (PNE), a partir de uma análise de dados da Pesquisa de Informações Básicas Municipais (Munic) e da Pesquisa de Informações Básicas Estaduais (Estadic) do ano de 2014, relativos à gestão democrática e aos critérios técnicos que acompanham a alocação de dirigentes escolares. De um lado, tem caráter eminentemente exploratório sobre as variáveis referentes à forma de provimento do cargo de diretor(a) escolar; de outro lado, busca analisar a associação entre as formas de preenchimento do cargo nas redes municipais de ensino considerando o tamanho do município, o Índice de Desenvolvimento Humano Municipal, as práticas que orientam o processo na rede estadual da unidade da Federação à qual o município

Resultados parciais deste trabalho foram apresentados no Seminário "Indicadores Educacionais e o Monitoramento do Plano Nacional de Educação”, realizado no Instituto Nacional de Estudos e Pesquisas Educacionais Anísio Teixeira (Inep), entre os dias 28 e 29 de novembro de 2017.

I Marcio Alexandre Barbosa Lima é doutor em sociologia pela Universidade de Brasília (UnB) e pesquisador do Instituto Nacional de Estudos e Pesquisas Educacionais Anísio Teixeira (Inep), atuando na Diretoria de Estudos Educacionais (Dired).

II Robson dos Santos é doutor em sociologia pela Universidade Estadual de Campinas (Unicamp) e pesquisador do Instituto Nacional de Estudos e Pesquisas Educacionais Anísio Teixeira (Inep), atuando na Diretoria de Estudos Educacionais (Dired). 
pertence e a frequência de reuniões dos conselhos municipais de educação. Além de investigar descritivamente se o processo de ocupação dos cargos de direção se dá por via de concurso, indicação, eleição ou outras formas e se há formação específica para o cargo, o trabalho buscou uma compreensão das características que se vinculam à prevalência das eleições para a escolha de diretores(as) das escolas públicas.

Palavras-chave: escola; gestão democrática; PNE.

\section{INTRODUÇÃO}

A Meta 19 do Plano Nacional de Educação - PNE (Brasil, 2014) estabeleceu o compromisso de que o Estado brasileiro deveria, no prazo de dois anos, "assegurar condições [...] para a efetivação da gestão democrática da educação, associada a critérios técnicos de mérito e desempenho e à consulta pública à comunidade escolar, no âmbito das escolas públicas, prevendo recursos e apoio técnico da União para tanto.” Isso consolida uma perspectiva histórica de valorização da gestão democrática e implica desafios às redes municipais e estaduais.

A meta combina a proposição de ampliação das formas democráticas de gestão das instituições escolares com a de maior profissionalização dos recursos humanos responsáveis pela administração das unidades escolares, por meio de critérios de mérito e desempenho. Dois desafios principais acompanham o monitoramento da Meta 19: definir a gestão democrática e construir indicadores, oriundos de bases de dados consistentes e contínuas, capazes de traduzir a existência dela nas escolas brasileiras.

Neste trabalho, foram analisados os dados da Pesquisa de Informações Básicas Municipais (Munic) e da Pesquisa de Informações Básicas Estaduais (Estadic) do ano de 2014 relativos à gestão democrática e aos critérios técnicos que acompanham a alocação de dirigentes escolares. Nesse sentido, as variáveis disponíveis referentes à forma de provimento do cargo de diretor(a) escolar e que constam nas mencionadas bases foram utilizadas buscando analisar a associação entre as formas de preenchimento do cargo nas redes municipais de ensino a partir do tamanho do município, do Índice de Desenvolvimento Humano Municipal (IDHM), das práticas que orientam o processo na rede estadual da unidade da Federação à qual o município pertence e da frequência de reuniões dos conselhos municipais de educação.

Este texto possui a seguinte composição: na parte inicial, são apresentadas definições de "gestão democrática" na Lei de Diretrizes e Bases da Educação (LDB) e nos dois últimos Planos Nacionais de Educação; em seguida, são apresentadas as 
bases de dados da Munic e da Estadic; na sequência, são descritas e analisadas as variáveis selecionadas, de modo a compor um panorama que caracterize as formas de provimento do cargo de diretor(a) nos municípios brasileiros; por fim, é elaborado um modelo de regressão logística, de modo a trazer elementos para compreensão das dimensões vinculadas às eleições como forma de escolha de diretores(as) das escolas públicas municipais.

\section{DEMOCRACIA, SOCIEDADE E INSTITUIÇÕES}

Os dados sobre a democracia em nível global revelam o crescimento do número de países democráticos nas últimas décadas ${ }^{1}$ : em 1975, havia 52 entre 160 países, o que representava 33\% do total; em 2015, de 204 países existentes, 125 eram considerados democráticos, ou seja, $65 \%$ dos países do globo.

Contudo, a definição do que é uma democracia permanece em disputa entre as diferentes correntes de pensamento. Na América do Sul, por exemplo, praticamente todos os países podem ser considerados democráticos se os critérios forem eleições livres, direito de organização política, direito de manifestação, acesso ao sistema judiciário ou outros elementos formais que caracterizam esse regime.

O surgimento de novas democracias em outras partes do mundo, contudo, tem colocado desafios para a teoria democrática, uma vez que critérios formais, abstratos e universais são insuficientes para avaliar a qualidade ou o significado da democracia em cada um desses países (Holston, 2001). Quanto mais países se tornam democráticos, mais surgem novos modelos de democracia, resultantes de diferentes histórias, culturas e arranjos institucionais; e eles trazem uma diversidade de situações, que a teoria democrática precisa compreender de modo a reformular seus modelos de análise.

Para Caldeira (1999), as democracias quase sempre são analisadas com base em modelos teóricos advindos de países europeus e norte-americanos; todavia, quando esses modelos são comparados com o desenvolvimento das novas democracias, percebe-se que elas diferem significativamente das experiências características dos países do norte (Holston, 2001; Caldeira, 1999). Da mesma forma, as experiências da cidadania não são as mesmas em todos os países e, ainda que existam direitos formais para todos os cidadãos, o acesso e o agenciamento de cada um deles ocorrem de maneira desigual.

Pensando dessa maneira, a qualidade da democracia está intrinsicamente relacionada à sociedade e seu contexto. Nesse sentido, ainda segundo Holston (2001), ultrapassar a cidadania formal e incorporar seus elementos substantivos requer uma

\footnotetext{
${ }^{1}$ Dados sobre democracias podem ser encontrados em: <https://freedomhouse.org/>.
} 
mudança cultural da sociedade, pois a democratização do Estado e da sociedade é mutuamente definida nessa perspectiva.

Se a definição de democracia é objeto de disputa entre teóricos e não há um modelo pronto implementado, quando o conceito é transposto ao campo da educação, em particular para a gestão, a pluralidade de definições se amplia. A Meta 19 do PNE (2014-2024) não proporciona todos os elementos para definir a gestão democrática. A Constituição Federal de 1988, assim como outros documentos legais, por exemplo, a LDB e os Planos Nacionais de Educação, trata do princípio democrático da educação e reafirma o princípio da democracia sem, contudo, definir seu conteúdo dentro de um modelo normativo, o que torna mais complexa a constituição de indicadores de monitoramento.

\section{GESTÃO DEMOCRÁTICA DA EDUCAÇÃO: DEFINIÇÕES E PERSPECTIVAS}

A Constituição Federal de 1988 afirma que a educação é um direito de todos e dever do Estado, visando ao pleno desenvolvimento da pessoa e seu preparo para o exercício da cidadania, baseada em princípios democráticos. A LDB, Lei $\mathrm{n}^{\circ}$ 9.394, delegou aos sistemas de ensino a definição sobre a forma da gestão democrática e estabeleceu a participação dos profissionais da educação na elaboração do projeto pedagógico da escola e a das comunidades escolar e local em conselhos escolares ou equivalentes. Estabelecidos esses dois critérios objetivos, o PNE (2001-2010), Lei $\mathrm{n}^{\mathrm{O}}$ 10.172, fixou como meta universalizar os conselhos escolares no ensino fundamental; e o PNE (2014-2024), Lei no 13.005, estabeleceu como meta a eleição de diretores(as) associada a critérios de mérito e desempenho nas escolas públicas (Gomes, 2015).

A ausência de uma regulamentação sobre os mecanismos de implementação da gestão democrática e a descentralização da sua efetivação para os sistemas estaduais e municipais de ensino permitiram que as escolas e os sistemas pudessem experimentar diversos desenhos institucionais de gestão democrática, combinando processos como a eleição ou outras formas de seleção de diretor(a) com distintos modelos de colegiados, consultivos ou deliberativos, com a participação de todos ou de apenas alguns segmentos da comunidade escolar. Essa possibilidade de moldar o próprio desenho institucional muitas vezes é avaliada de maneira negativa, visto que sistemas deixam de efetivar a participação ou a desenvolvem parcialmente. Em certa medida, esse cenário decorre da pluralidade de concepções sobre gestão democrática.

No material para o curso de especialização em gestão escolar da Escola de Gestores da Educação Básica do Ministério da Educação (MEC), por exemplo, o manual utilizado apresenta as diferentes concepções de gestão democrática, de modo a tornar explícito o conjunto de visões que envolvem a temática (Quadro 1). 


\section{QUADRO 1}

\section{DEFINIÇÕES DE GESTÃO DEMOCRÁTICA}

\section{Definições}

Um processo contínuo, gerador de uma nova experiência de gestão política, que nasce da consciência crítica elaborada na ação e no debate. Na escola, a gestão estaria assim, nas mãos de todos os participantes e envolvidos nas atividades educativas, isto é, professores, pais e comunidade e não apenas de um conselho ou diretor. (Schlesener, 2006).

É um processo de aprendizado e de luta política que não se circunscreve aos limites da prática educativa, mas vislumbra, nas especificidades dessa prática social e de sua relativa autonomia, a possibilidade de criação de canais de efetiva participação e de aprendizado no "jogo" democrático e, consequentemente, do repensar das estruturas de poder autoritário que permeiam as relações sociais e, no seio dessas, as práticas educativas. (Dourado, 2006).

É um conjunto de procedimentos que inclui todas as fases do processo de administração desde a concepção de diretrizes da política educacional, passando pelo planejamento e definições de programas, projetos e metas educacionais, até as suas respectivas implementações e procedimentos avaliativos. (Mendonça, 2000).

Um conjunto de transformações que compreende a instalação de conselhos deliberativos, constituídos por representantes de diversos segmentos da comunidade escolar e também a autonomia financeira representada pelo repasse direto de recursos financeiros a escola e a delegação a ela da responsabilidade pela forma de utilização desses recursos. (Torres; Graske, 2000).

Fonte: Elaboração própria.

As definições de gestão democrática apresentam nuances e diferenças, todavia são comuns os temas da participação, do planejamento e da autonomia. Sob o ponto de vista da operacionalização institucional desses temas, outro manual de formação técnica do Ministério da Educação, destaca:

A gestão democrática implica um processo de participação coletiva. Sua efetivação na escola pressupõe instâncias colegiadas de caráter deliberativo, bem como a implementação do processo de escolha de dirigentes escolares, além da participação de todos os segmentos da comunidade escolar na construção do projeto político-pedagógico e na definição da aplicação dos recursos recebidos pela escola. (Oliveira; Moraes; Dourado, 2008, p. 4).

Todas essas concepções sobre o que é a gestão democrática da educação devem ser analisadas considerando-se uma distinção fundamental: as definições apresentadas estão diretamente vinculadas às escolas e à pratica local, não se referem aos outros fóruns dos sistemas de ensino.

Apesar do caráter fundamental da escola para o desenvolvimento e o preparo para a cidadania, é preciso considerar que a gestão democrática possui uma dimensão institucional mais complexa, como os Conselhos Nacional, Estaduais e Municipais de Educação, o Fórum Nacional de Educação, os Congressos Nacionais de Educação e 
outros espaços de participação democrática na gestão da educação em outras esferas. Esses espaços de representação da sociedade civil são fundamentais para a democratização da educação, contudo, o preparo para o exercício da cidadania tem como locus a escola, onde funcionam diversos mecanismos de participação estabelecidos historicamente.

Ainda que não exista um modelo único de gestão escolar, categorias como eleição, colegialidade e participação estão presentes na maioria das análises sobre gestão democrática da escola (Oliveira; Moraes; Dourado, 2008; Dourado, 2011). Além dessas três categorias, temas como autonomia financeira, administrativa e pedagógica, ao lado de transparência e pluralidade, ocupam um espaço importante no debate (Gracindo, 2007). A gestão democrática, portanto, envolve a reflexão e o debate sobre essas categorias fundamentais e sobre a melhor forma de garantir a efetiva participação da comunidade escolar.

Dentre os mecanismos institucionais de participação estão: o grêmio estudantil direito dos estudantes, criado pela Lei $n^{0}$ 7.398/85 e constituído como uma entidade autônoma e representativa dos seus interesses; e a associação de pais e mestres - regulamentada por legislação estadual e também constituída historicamente. Além desses, o conselho escolar, o conselho de classe e a forma de escolha de diretor(a) representam mecanismos importantes de democratização da gestão escolar. Contudo, o funcionamento de cada um deles não ocorre em todas as escolas do País e, quando acontece, não se faz de maneira linear e homogênea. Também não há informações disponíveis a respeito da existência e do funcionamento desses mecanismos em todas as escolas nacionais.

Os mecanismos já citados, ao lado do projeto político-pedagógico (PPP), são importantes, mas a eleição de diretores(as) e os conselhos escolares são os mais relevantes e debatidos no que diz respeito à gestão democrática. A escolha de diretor(a) pode ser feita por indicação do poder municipal ou local; concurso; eleição pela comunidade; ou combinação de mais de uma dessas. A forma mais comum de escolha é a indicação política do dirigente municipal ou estadual; esta pode favorecer o clientelismo e as relações patrimonialistas à medida que o(a) diretor(a) não deve satisfações de seus atos à comunidade escolar, mas ao dirigente que o nomeou. Como a escola é uma instituição com grande potencial de agregar pessoas e votos, a escolha de diretor(a) pode ser determinada por esses valores externos a ela.

A seleção de diretor(a) por meio de concurso público representou um avanço em relação ao processo de indicação política, no que se refere à equidade e à isonomia entre os candidatos. Todavia, os processos seletivos realizados mediante concursos são capazes de aferir a capacidade intelectual dos candidatos, mas não sua liderança, além de não envolverem a participação da comunidade na escolha. Dessa forma, há a possibilidade de o(a) diretor(a) concursado(a) também gerir a escola de maneira personalista e sem capacidade de promover a participação de todos. Por isso, a seleção por meio de concurso não garante a gestão democrática, uma vez que esta depende da participação da comunidade escolar. 
A eleição de diretores(as), longe de ser um consenso, enfrenta algumas dificuldades em relação aos seus objetivos de democratização. O processo eleitoral pode acabar reproduzindo vícios políticos como manifestações de personalismo, populismo, falta de preparo do eleito e reprodução de práticas clientelísticas. Quando associada a processos seletivos, a eleição não impede a indicação ou as práticas tradicionais da política ${ }^{2}$.

Num processo eleitoral acirrado, há também a possibilidade de rompimento dos laços de amizade e solidariedade em função das disputas, causando repercussões no âmbito escolar como um todo, por exemplo, boicotes e perseguições. Por isso, a eleição de diretores(as) por si só não é capaz de democratizar a gestão escolar, caso a democracia seja entendida como a participação de todos nos processos de decisão e deliberação da vida escolar em diversos aspectos.

A participação da comunidade pode ocorrer durante processos eleitorais, mas para ser efetivada deve estar institucionalizada em outros mecanismos existentes, como o conselho escolar - este tem atribuições consultivas, deliberativas, fiscais e geralmente envolve aspectos pedagógicos, administrativos e financeiros (Libâneo, 2008). Normalmente eleito no começo do ano, o conselho pode ter uma composição diversa entre membros da comunidade escolar, abrangendo ou não todos os segmentos: pais, professores, alunos, funcionários e comunidade local. Além disso, o conselho escolar representa espaço participativo mais efetivo do que a eleição, que acontece num breve período determinado e após cada mandato terminar.

Importante observar que a aprovação e o monitoramento do projeto pedagógico se dão no âmbito do conselho escolar, o que evidencia a prevalência do fórum de deliberação em relação ao próprio projeto a ser analisado e aprovado pelos participantes.

Além do conselho escolar, o conselho de classe também possui atribuições consultivas e deliberativas relacionadas a assuntos didático-pedagógicos, ao projeto político-pedagógico e ao regimento escolar. O conselho de classe discute alternativas que busquem garantir a efetivação do processo de ensino e aprendizagem dos estudantes e, numa forma participativa, deve incluir todos os segmentos da comunidade escolar, sem distinção. Contudo, normalmente, sua composição é apenas de professores, equipe pedagógica e direção, excluindo a participação de pais, alunos e funcionários.

Eleição, colegiado e participação, como elementos definidores da gestão democrática, apresentam uma variedade de desenhos institucionais, a partir da realidade de cada escola e de cada sistema de ensino. Questões como o quórum necessário para deliberar, os potenciais eleitores, o peso do voto de cada segmento ou indivíduo na composição do resultado final, a responsabilidade de elaborar a agenda do conselho, a duração do mandato e a forma de campanha devem ser discutidas e possuem grande

\footnotetext{
2 Para talvez superar parte desses problemas, os critérios estabelecidos no Plano Nacional de Educação associam a eleição de dirigentes a mérito e desempenho, prevendo, entre suas estratégias, a criação de uma prova nacional específica.
} 
impacto na qualidade da participação e na construção dos desenhos institucionais desta. Além das apresentações normativas sobre o que deveria ser uma gestão democrática, alguns autores analisam o processo de funcionamento da gestão escolar, observando sua prática no âmbito da escola pública (Paro, 1992; Mendonça, 2001; Lima, 2014; Gutierrez; Catani, 1998; Dalberio, 2009).

A comparação entre os mecanismos de democratização da gestão da escola revela que a eleição de diretor(a) é importante, mas a efetivação da gestão democrática ocorre, sobretudo, nos colegiados. Para Gutierrez e Catani (1998), participação significa construir coletivamente o consenso como plano de ação. Nesse caso, significa que todos os membros da comunidade escolar podem contribuir com igualdade de condições no processo de formação das decisões.

A participação da comunidade pode muitas vezes ficar restrita a trabalhos voluntários e de manutenção física da escola. Mas vale ressaltar que essa participação pode gerar um sentimento de pertencimento entre os voluntários capaz de envolvê-los na busca de soluções para diversos outros problemas enfrentados no cotidiano escolar.

Há também a possibilidade de haver um conselho formal na escola, mas sem participação efetiva capaz de interferir nas decisões cotidianas da instituição: um conselho burocrático, com funções protocolares e legitimadoras das ações da direção escolar e que muitas vezes se reúne em horários que não permitem a participação dos pais.

Além dessas situações, é comum no discurso dos membros da equipe escolar a afirmação de que a comunidade é despreparada para participar, não tem consciência da importância das reuniões e possui uma inclinação para comodismo, passividade, conformismo, apatia e desinteresse em participar (Paro, 1992; Mendonça, 2001; 2000). Nesses discursos, evidencia-se a vivência da cidadania apenas de maneira formal, na qual a participação não tem efetividade e as decisões não são realmente deliberadas de maneira coletiva.

Esse processo de definição do significado da gestão democrática na escola pública e a construção dos mecanismos de efetivação da participação são produtos da experiência histórica brasileira, marcadamente a partir da redemocratização do País. Embora não haja um modelo de gestão democrática único, as discussões em torno da eleição de diretores(as) da educação marcaram o debate histórico sobre o tema da gestão escolar.

A seguir, a discussão se desdobra sobre a análise dos dados da Munic e da Estadic relativos à gestão democrática, especificamente aos critérios técnicos que acompanham a alocação de dirigentes escolares nos municípios brasileiros no ano de 2014. O processo de escolha de diretores(as) das escolas públicas por meio de eleições representa um avanço em relação à legislação passada e uma conquista histórica dos movimentos de defesa da democracia, ainda que a efetivação da participação ocorra também por meio de outros fóruns e mecanismos participativos. 


\section{ANÁLISE DAS FORMAS DE PROVIMENTO DO CARGO DE DIREÇÃO DAS ESCOLAS}

Como já dito, um dos maiores obstáculos ao monitoramento da Meta 19 do Plano Nacional de Educação é a ausência de dados relacionados aos diversos aspectos da gestão democrática. O Sistema de Avaliação da Educação Básica (Saeb), por exemplo, possui questionários contextuais para diretores(as), professores(as) e alunos(as) que contemplam itens relacionados à participação, como forma de escolha de diretores(as) de escolas, elaboração do projeto político-pedagógico, existência, composição e funcionamento do conselho escolar e outros temas importantes referentes às estratégias da Meta 19.

Além dos questionários contextuais do Saeb, desde 2014, ano da aprovação do PNE, o Instituto Brasileiro de Geografia e Estatística (IBGE) passou a coletar informações a respeito de formas de seleção de diretores(as), existência e funcionamento dos conselhos de educação, entre outros temas relacionados à gestão democrática. A Munic e a Estadic são publicadas desde 2001, e um dos seus eixos temáticos é a educação, oferecendo elementos de análise sobre como são governados estados e municípios. Seus resultados estão agregados por faixas de tamanho populacional dos municípios, grandes regiões e unidades da Federação. Para a realização das pesquisas, em 2014, o IBGE considerou o Plano Nacional da Educação, especialmente a Meta 19.

Utilizando essas bases de dados, além de conhecer descritivamente se o processo de ocupação dos cargos de diretores(as) se dá por via de concurso, indicação, eleição ou outras formas e se há formação específica para o exercício do cargo, a análise também busca uma compreensão dos processos que se vinculam à prevalência de cada uma das formas de ocupação, de modo a compor um panorama que caracterize os municípios brasileiros.

A consolidação da democracia e da gestão democrática requer um contexto que possibilite e induza práticas democráticas, bem como disponha das condições legais, políticas e culturais que fomentem essa gestão. Por isso, os dados relacionados com a forma de escolha de diretores(as) foram analisados considerando outras dimensões, como o tamanho do município, os níveis de desenvolvimento humano, a existência de conselhos municipais de educação e as formas de escolha praticadas pelo estado ao qual o município pertence, informações contidas em outras bases de dados.

Do ponto de vista institucional, o tamanho populacional do município pode indicar a existência de estruturas administrativas e de recursos humanos necessários à composição de processos como concurso, eleições ou indicações no preenchimento do cargo de diretor(a) de escola. O desenvolvimento humano, por sua vez, revela as condições referentes à renda, escolarização e saúde da população de um município, o que pode acarretar desigualdades no exercício da cidadania.

Enquanto a Munic e a Estadic coletam as informações de natureza administrativa dos estados e municípios brasileiros, o Índice de Desenvolvimento Humano 
Municipal (IDHM) apresenta informações de natureza social importantes acerca do desenvolvimento econômico de uma localidade.

O Índice de Desenvolvimento Humano (IDH) foi criado na década de 1990 no âmbito do Programa das Nações Unidas para o Desenvolvimento (Pnud) e popularizou-se como medida do grau de desenvolvimento de um país, em alternativa ao Produto Interno Bruto. O IDH reúne três indicadores: saúde (expectativa de vida da população), educação (anos médios de estudos) e renda (Produto Interno Bruto per capita). Segundo seus idealizadores, o conceito de desenvolvimento humano "[...] deve ser centrado nas pessoas e na ampliação do seu bem-estar, entendido não como o acúmulo de riqueza e o aumento da renda, mas como a ampliação do escopo das escolhas e da capacidade e da liberdade de escolher" (Pnud, 2013, p. 23). Dentro dessa liberdade de escolhas e da capacidade de escolher referidas pelo IDH está a participação nas decisões públicas.

Em 2013, em parceria com o Instituto de Pesquisa Econômica Aplicada (Ipea), foi criado o IDHM dos 5.565 municípios brasileiros, a partir de dados do Censo Demográfico de 2010. O IDHM brasileiro considera as mesmas três dimensões do IDH, porém, com adequações da metodologia internacional ao contexto nacional e aos dados disponíveis. O IDHM, assim como o IDH, é um número que varia entre 0 e 1: quanto mais próximo de 1, maior o desenvolvimento humano de um município. Considerando essas definições, pessoas que vivem em municípios de alto IDHM possuem mais e melhores condições socioeconômicas e, de modo inverso, municípios com baixo IDHM possuem menores condições.

As análises de dados foram feitas considerando a discussão sobre gestão democrática e as teorias sobre democracia. Um dos temas fundantes desse debate está relacionado ao tamanho de população, território e delegação. Na antiguidade, a quantidade de participantes ou o tamanho do território não representaram um obstáculo às decisões e à participação, mas em sociedades contemporâneas esses temas foram fundamentais para o surgimento da democracia representativa (Madison; Jay, 1985). Em linhas gerais, a teoria democrática discute a relação entre a escala do território ou da população e a efetividade da participação nas decisões políticas.

Muitos consideram que em grupos menores as possibilidades de participação e de influência na decisão são maiores em comparação aos grandes aglomerados (Dahl, 1988; Pateman, 1980). Por outro lado, em realidades como a brasileira, a desigualdade social tem impacto sobre a participação e a democracia. Dessa forma, enquanto parcela da teoria democrática destaca que os pequenos territórios representam o locus privilegiado à participação, a pobreza e a falta de infraestrutura influenciam de forma significativa a participação nos espaços destinados à cidadania (Avritzer; Ramos, 2016).

Além de considerar o tamanho do município e seus respectivos IDHMs, outro fator importante para a análise é a influência das redes estaduais sobre as municipais, sendo permitido ao município, inclusive, “[...] optar, ainda, por se integrar ao sistema 
estadual de ensino ou compor com ele um sistema único de educação básica” (Brasil, 1996, art. 11). A relação entre descentralização e centralização da educação possui uma longa e tensa história no Brasil. Assim, a influência da rede estadual deve ser considerada como fator adicional na forma de seleção de diretores(as) de escolas municipais.

Outra importante informação para avaliar a gestão democrática da educação é a existência dos CMEs e a frequência de suas reuniões. Esses conselhos tiveram seu maior crescimento no ano seguinte à promulgação da LDB/96. A existência de conselhos municipais de educação, assim como a quantidade de suas reuniões anuais, permite aferir o grau de maturidade e participação em cada município. É esperado que a existência de um conselho municipal ativo, com uma grande frequência de reuniões, represente uma maior tendência na implementação da meta e das estratégias relacionadas à gestão democrática. Desse modo, foi analisada a associação entre as formas de preenchimento do cargo de diretor(a) nas redes municipais de ensino, considerando o tamanho da população, o Índice de Desenvolvimento Humano Municipal, a forma de escolha de diretores(as) de escolas públicas da rede estadual do município e a frequência de reuniões dos conselhos municipais de educação.

\section{FORMAS DE PROVIMENTO DO CARGO DE DIRETOR(A) NOS ESTADOS}

Segundo os dados da Estadic 2014, a eleição é a forma de escolha mais frequente nos estados da Federação: entre os 26, 8 (30\%) deles (Rondônia, Acre, Alagoas, Sergipe, Rio Grande do Sul, Mato Grosso do Sul, Mato Grosso e Goiás), além do Distrito Federal, realizam eleições como forma de escolha de diretores(as) de escolas públicas estaduais; outros 6 (22\%) estados (Pará, Amapá, Piauí, Rio Grande do Norte, Paraíba e Bahia) adotam eleição e indicação ao mesmo tempo; e 1 (Ceará) utiliza eleição e outras formas não definidas no questionário. Assim, mais da metade dos estados (15) realizam a consulta à comunidade como uma das etapas de escolha de diretores(as) estaduais (Tabela 1).

Importante frisar que diversos estados alteraram suas legislações em decorrência da aprovação dos respectivos planos estaduais a partir de 2014, de forma que os dados representam o momento anterior a essa aprovação.

A indicação de diretores(as) das escolas estaduais ocorria em 4 (9\%) estados da região Norte (Amazonas, Roraima, Tocantins e Maranhão), mesma quantidade daqueles que empregam outra forma de escolha não presente no questionário (Pernambuco, Minas Gerais, Espírito Santo e Santa Catarina); 1 estado (Paraná) utiliza a indicação e outra forma de escolha combinada e não prevista no questionário aplicado. O concurso aparece em apenas $2(7 \%)$ estados da Federação, que pertencem à região Sudeste (Rio de Janeiro e São Paulo). 
TABELA 1

FORMAS DE NOMEAÇÃO DE DIRETORES(AS) DOS ESTADOS - BRASIL

\begin{tabular}{|c|c|c|c|c|c|c|c|}
\hline UF & $\begin{array}{c}\text { Exclusivamente } \\
\text { indicação }\end{array}$ & $\begin{array}{c}\text { Exclusivamente } \\
\text { eleição }\end{array}$ & $\begin{array}{c}\text { Exclusivamente } \\
\text { concurso }\end{array}$ & $\begin{array}{c}\text { Exclusivamente } \\
\text { outros }\end{array}$ & $\begin{array}{c}\text { Misto } \\
\text { (indicação } \\
\text { e eleição) }\end{array}$ & $\begin{array}{c}\text { Misto } \\
\text { (indicação } \\
\text { e outros) }\end{array}$ & $\begin{array}{c}\text { Misto } \\
\text { (eleição } \\
\text { e outros) }\end{array}$ \\
\hline Rondônia & - & Sim & - & - & - & - & - \\
\hline Acre & - & Sim & - & - & - & - & - \\
\hline Amazonas & Sim & - & - & - & - & - & - \\
\hline Roraima & Sim & - & - & - & - & - & - \\
\hline Pará & - & - & - & - & Sim & - & - \\
\hline Amapá & - & - & - & - & Sim & - & - \\
\hline Tocantins & Sim & - & - & - & - & - & - \\
\hline Maranhão & Sim & - & - & - & - & - & - \\
\hline Piauí & - & - & - & - & Sim & - & - \\
\hline Ceará & - & - & - & - & - & - & Sim \\
\hline $\begin{array}{l}\text { Rio Grande } \\
\text { do Norte }\end{array}$ & - & - & - & - & Sim & - & - \\
\hline Paraíba & - & - & - & - & Sim & - & - \\
\hline Pernambuco & - & - & - & Sim & - & - & - \\
\hline Alagoas & - & Sim & - & - & - & - & - \\
\hline Sergipe & - & Sim & - & - & - & - & - \\
\hline Bahia & - & - & - & - & Sim & - & - \\
\hline $\begin{array}{l}\text { Minas } \\
\text { Gerais }\end{array}$ & - & - & - & Sim & - & - & - \\
\hline $\begin{array}{l}\text { Espírito } \\
\text { Santo }\end{array}$ & - & - & - & Sim & - & - & - \\
\hline $\begin{array}{l}\text { Rio de } \\
\text { Janeiro }\end{array}$ & - & - & Sim & - & - & - & - \\
\hline São Paulo & - & - & Sim & - & - & - & - \\
\hline Paraná & - & - & - & - & - & Sim & - \\
\hline $\begin{array}{l}\text { Santa } \\
\text { Catarina }\end{array}$ & - & - & - & Sim & - & - & - \\
\hline $\begin{array}{l}\text { Rio Grande } \\
\text { do Sul }\end{array}$ & - & Sim & - & - & - & - & - \\
\hline $\begin{array}{l}\text { Mato Grosso } \\
\text { do Sul }\end{array}$ & - & Sim & - & - & - & - & - \\
\hline Mato Grosso & - & Sim & - & - & - & - & - \\
\hline Goiás & - & Sim & - & - & - & - & - \\
\hline $\begin{array}{l}\text { Distrito } \\
\text { Federal }\end{array}$ & - & Sim & - & - & - & - & - \\
\hline
\end{tabular}

Fonte: Elaboração própria com base em dados da Estadic (IBGE, 2014b).

A distribuição regional revela que a escolha de diretores(as) das escolas estaduais por meio de consulta à comunidade ocorre com maior frequência no CentroOeste, seguido das regiões Nordeste e Norte (Tabela 2). 
TABELA 2

FORMAS DE ESCOLHA DE DIRETORES(AS) DAS ESCOLAS ESTADUAIS, POR GRANDES REGIÕES - BRASIL

\begin{tabular}{|c|c|c|c|c|c|c|c|}
\hline $\begin{array}{l}\text { Grandes } \\
\text { Regiôes }\end{array}$ & $\begin{array}{c}\text { Exclusivamente } \\
\text { indicação }\end{array}$ & $\begin{array}{c}\text { Exclusivamente } \\
\text { eleição }\end{array}$ & $\begin{array}{c}\text { Exclusivamente } \\
\text { concurso }\end{array}$ & $\begin{array}{c}\text { Exclusivamente } \\
\text { outros }\end{array}$ & $\begin{array}{c}\text { Misto } \\
\text { (indicação } \\
\text { e eleição) }\end{array}$ & $\begin{array}{c}\text { Misto } \\
\text { (indicação } \\
\text { e outros) }\end{array}$ & $\begin{array}{c}\text { Misto } \\
\text { (eleição } \\
\text { e outros) }\end{array}$ \\
\hline Sul & $0 \%$ & $33 \%$ & $0 \%$ & $33 \%$ & $0 \%$ & $33 \%$ & $0 \%$ \\
\hline Sudeste & $0 \%$ & $0 \%$ & $50 \%$ & $50 \%$ & $0 \%$ & $0 \%$ & $0 \%$ \\
\hline
\end{tabular}

Fonte: Elaboração própria com base em dados da Munic (IBGE, 2014a).

Dos 7 estados da região Norte, 4 realizam eleições como uma das etapas de seleção, enquanto os outros 3 utilizam a indicação como forma de escolha de diretores(as). Os estados de Rondônia e Acre realizam exclusivamente eleições, enquanto Pará e Amapá combinam eleições e indicação. A utilização exclusiva da indicação ocorre apenas nos estados do Amazonas, Roraima e Tocantins.

Dos 9 estados da região Nordeste, 6 realizam eleições como uma das etapas de escolha de diretores(as). Os estados que combinam a indicação e as eleições são Piauí, Rio Grande do Norte, Paraíba e Bahia. A eleição como forma exclusiva ocorre em Sergipe e Alagoas, enquanto que o Ceará combina eleições e outra forma não prevista no questionário. A indicação exclusiva ocorre apenas no estado do Maranhão; e Pernambuco realiza outra forma de escolha de diretores(as) não contemplada no questionário aplicado.

Na região Centro-Oeste, todos os estados e o Distrito Federal realizam eleições como forma de escolha de diretores(as). Na região Sudeste, como observado, São Paulo e Rio de Janeiro utilizam o concurso, enquanto Minas Gerais e Espírito Santo realizam outra forma de escolha de diretores(as) não prevista no questionário.

Na região Sul, o estado do Rio Grande do Sul realiza exclusivamente eleições; o Paraná utiliza a indicação associada a outra forma; e Santa Catarina emprega outra forma de escolha de diretores(as) não prevista no questionário aplicado.

Assim, a distribuição regional das diversas formas de escolha de diretores(as) revela que a indicação como forma exclusiva de seleção ocorre predominantemente na região Norte (Amazonas, Roraima e Tocantins); a eleição como etapa única se concentra na região Centro-Oeste (Mato Grosso do Sul, Mato Grosso, Goiás e Distrito Federal); enquanto no Nordeste, em 7 estados (Alagoas, Sergipe, Ceará, Piauí, Rio Grande do Norte, Paraíba e Bahia), a eleição é uma das etapas do seu processo de seleção.

Logo após o levantamento sobre a forma de escolha, o questionário da Estadic coleta informações a respeito da participação em programa de formação em gestão escolar para diretores(as) de escolas estaduais. Ao lado da consulta pública, critérios de mérito e desempenho são previstos no cumprimento da Meta 19. 
Como a definição sobre quais são esses critérios de mérito e desempenho pode variar significativamente entre os entes federativos, a participação em programa de formação em gestão escolar é uma dessas formas possíveis, certamente não a única e nem suficiente para contemplar o texto legal. Assim, considerando essa participação como uma forma de avaliar os critérios de mérito e desempenho previstos no PNE, a Tabela 3 traz os seguintes resultados:

TABELA 3

\section{FORMA DE ESCOLHA DE DIRETORES(AS) E NECESSIDADE DE PARTICIPAÇÃO EM PROGRAMA DE FORMAÇÃO EM GESTÃO ESCOLAR - BRASIL}

\begin{tabular}{|l|c|c|} 
& Não obrigatório & Obrigatório \\
\hline Exclusivamente indicação & 2 & 2 \\
\hline Exclusivamente eleição & 3 & 6 \\
\hline Exclusivamente concurso & 1 & 1 \\
\hline Exclusivamente outros & 2 & 2 \\
\hline Misto (indicação e eleição) & 1 & 5 \\
\hline Misto (indicação e outros) & 1 & 0 \\
\hline Misto (eleição e outros) & 1 & 0 \\
\hline Total & 11 & 16 \\
\hline
\end{tabular}

Fonte: Elaboração própria com base em dados da Estadic (IBGE, 2014b).

Nos estados do Acre, Amazonas, Roraima, Pará, Amapá, Piauí, Rio Grande do Norte, Pernambuco, Sergipe, Bahia, Rio de Janeiro, Santa Catarina, Mato Grosso do Sul, Mato Grosso e Goiás e no Distrito Federal, é necessária a participação em programa de formação em gestão escolar para exercer o cargo de diretor(a) - dentre os 16 entes com essa obrigatoriedade, 11 (68\%) utilizam as eleições como uma das etapas do processo de seleção de diretores(as) das escolas públicas estaduais. Nos estados de Rondônia, Tocantins, Maranhão, Ceará, Paraíba, Alagoas, Minas Gerais, Espírito Santo, São Paulo, Paraná e Rio Grande do Sul, não é necessária a participação em programa de formação em gestão escolar para exercer o cargo de diretor(a) de escola da rede estadual - desses 11 estados, 4 (36\%) realizam eleições como uma de suas etapas no processo de seleção. Ou seja, observa-se que apenas 11(40\%) unidades da Federação selecionam diretores(as) por meio de consulta à comunidade e de critérios de mérito e desempenho simultaneamente: Acre, Pará, Amapá, Piauí, Rio Grande do Norte, Sergipe, Bahia, Mato Grosso do Sul, Mato Grosso, Goiás e Distrito Federal.

\section{FORMAS DE PROVIMENTO DO CARGO DE DIRETOR(A) ESCOLAR NOS MUNICÍPIOS}

Quando essas questões são colocadas em termos municipais, o quadro é relativamente diferente. Nos questionários da Munic, assim como nos da Estadic, as 
possíveis respostas sobre a forma de escolha de diretores(as) de escolas eram quatro: indicação, eleição, concurso e outra forma - mas era possível selecionar mais de uma delas (Tabela 4).

TABELA 4

FORMA DE ESCOLHA DE DIRETORES(AS) DE ESCOLAS DA REDE MUNICIPAL - BRASIL -2014

\begin{tabular}{|l|c|c|}
\hline & Total & $\%$ \\
\hline Exclusivamente indicação & 4146 & 74,4 \\
\hline Exclusivamente eleição & 693 & 12,4 \\
\hline Exclusivamente concurso & 200 & 3,6 \\
\hline Exclusivamente outros & 168 & 3,0 \\
\hline Misto (concurso, indicação e eleição) & 2 & 0,0 \\
\hline Misto (concurso, indicação e outros) & 3 & 0,1 \\
\hline Misto (concurso e indicação) & 59 & 1,1 \\
\hline Misto (indicação e eleição) & 204 & 3,7 \\
\hline Misto (indicação e outros) & 53 & 1,0 \\
\hline Misto (indicação, eleição e outros) & 2 & 0,0 \\
\hline Misto (eleição e concurso) & 15 & 0,3 \\
\hline Misto (eleição e outros) & 11 & 0,2 \\
\hline Misto (concurso e outros) & 9 & 0,2 \\
\hline Não respondeu nenhuma & 5 & 0,1 \\
\hline Total & 5570 & 100,0 \\
\hline
\end{tabular}

Fonte: Elaboração própria com base em dados da Munic (IBGE, 2014a).

A indicação é a forma mais presente nos municípios brasileiros $(74,4 \%)$, seguida de eleição $(12,4 \%)$, concurso $(3,6 \%)$ e outras formas $(3 \%)$. Respostas múltiplas sobre a forma de escolha de diretores(as) representaram $6,5 \%$ do total das respostas, 363 municípios (Tabela 4). Nesses casos, a combinação mais frequente foi entre indicação e eleição $(3,75 \%)$, seguida de concurso e indicação $(1,1 \%)$ e indicação e outras formas $(1,0 \%)$. Para fins de análise, agregaram-se essas possibilidades do seguinte modo: eleição e outras formas, indicação e outras formas, concurso e outras formas. Dessa maneira, 16,6\% dos municípios utilizam a eleição como uma das etapas de escolha de diretores(as) de escolas das redes municipais, conforme a Tabela 4.

Com relação aos critérios de mérito e desempenho previstos no PNE, a obrigatoriedade de participação em programa de formação em gestão escolar foi considerada como parâmetro para avaliá-los, assim como na Estadic. Logo após o levantamento sobre a forma de escolha de diretores(as) das escolas públicas municipais, o questionário da Munic perguntava ao entrevistado a respeito da obrigatoriedade da participação em programa de formação em gestão escolar. Segundo os dados desta pesquisa, em todo o País, apenas 1.540 municípios $(27,6 \%)$ estabelecem essa participação, inde- 
pendentemente da forma de escolha, como condição para o exercício do cargo de diretor(a), conforme Tabela 5 .

TABELA 5

FORMAS DE ESCOLHA DE DIRETORES(AS) E NECESSIDADE DE PARTICIPAÇÃO EM PROGRAMA DE FORMAÇÃO EM GESTÃO ESCOLAR - BRASIL

\begin{tabular}{|c|c|c|c|c|}
\hline & & Não obrigatório & Obrigatório & Total \\
\hline \multirow{2}{*}{ Exclusivamente indicação } & Total & 3109 & 1037 & 4146 \\
\hline & $\%$ & $75 \%$ & $25 \%$ & $100 \%$ \\
\hline \multirow{2}{*}{ Exclusivamente eleição } & Total & 449 & 244 & 693 \\
\hline & $\%$ & $65 \%$ & $35 \%$ & $100 \%$ \\
\hline \multirow{2}{*}{ Exclusivamente concurso } & Total & 142 & 58 & 200 \\
\hline & $\%$ & $71 \%$ & $29 \%$ & $100 \%$ \\
\hline \multirow{2}{*}{ Exclusivamente outros } & Total & 97 & 71 & 168 \\
\hline & $\%$ & $58 \%$ & $42 \%$ & $100 \%$ \\
\hline \multirow{2}{*}{ Eleição e outras formas } & Total & 150 & 84 & 234 \\
\hline & $\%$ & $64 \%$ & $36 \%$ & $100 \%$ \\
\hline \multirow{2}{*}{ Indicação e outras formas } & Total & 73 & 42 & 115 \\
\hline & $\%$ & $63 \%$ & $37 \%$ & $100 \%$ \\
\hline \multirow{2}{*}{ Misto (concurso e outras formas) } & Total & 5 & 4 & 9 \\
\hline & $\%$ & $56 \%$ & $44 \%$ & $100 \%$ \\
\hline \multirow{2}{*}{ Não respondeu nenhuma } & Total & 1 & 0 & 5 \\
\hline & $\%$ & $20 \%$ & $0 \%$ & $100 \%$ \\
\hline \multirow{2}{*}{ Total } & Total & 4026 & 1540 & 5570 \\
\hline & $\%$ & $72 \%$ & $28 \%$ & $100 \%$ \\
\hline
\end{tabular}

Fonte: Elaboração própria com base em dados da Munic (IBGE, 2014a).

Apenas 35\% dos municípios que selecionam diretores(as) por meio de eleição possuem a obrigatoriedade da participação em programa de formação em gestão escolar, o que representa 4,4\% do total de municípios do País. Estes 244 municípios seriam, caso fosse adotado exclusivamente esse critério para o monitoramento da Meta 19 do PNE, os que, em 2014, cumpriam o estabelecido.

Contudo, a obrigatoriedade de participação em programa de formação como critério único para avaliar mérito e desempenho previstos na meta elimina todas as outras possibilidades e entendimentos sobre seus significados. Considerando os números e esse entendimento, utilizou-se apenas o critério de consulta à comunidade nas análises subsequentes. Assim, quando se observa a distribuição das formas de escolha de diretores(as) das escolas municipais por estado e região, é possível identificar a importância da rede estadual nesse resultado. O Gráfico 1 apresenta os percentuais dos municípios em cada unidade da Federação a partir das formas de escolha de diretores(as) de escolas. A Tabela 6 apresenta os percentuais de municípios em cada região considerando as formas de escolha de diretores(as) das escolas municipais. 


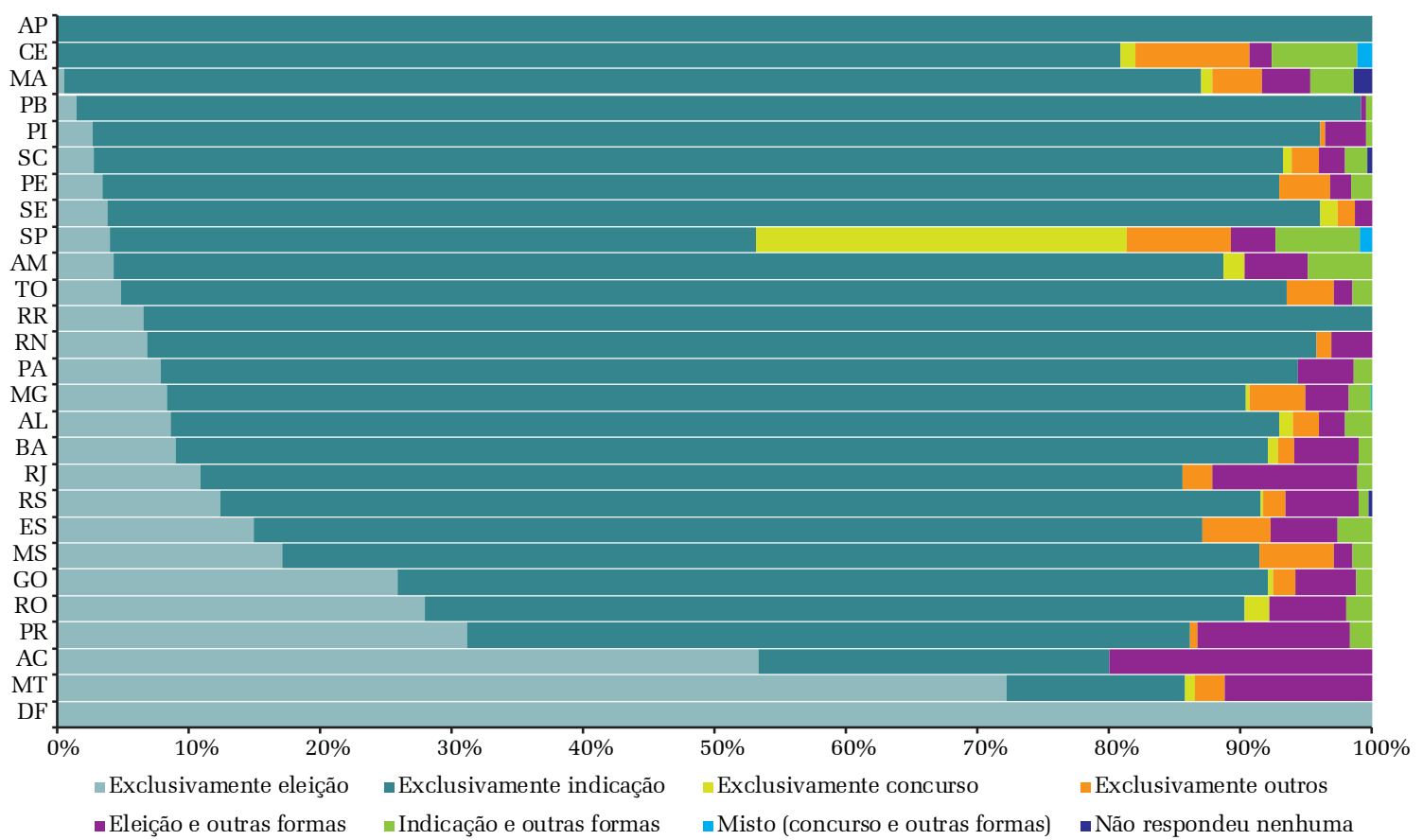

GRÁFICO 1

\section{AS FORMAS DE SELEÇÃO DE DIRETORES(AS) DE ESCOLAS NOS MUNICÍPIOS, POR UNIDADE DA FEDERAÇÃO - BRASIL - 2014}

Fonte: Elaboração própria com base em dados da Munic (IBGE, 2014a).

Em destaque, observa-se o percentual de municípios nos estados do Acre e do Mato Grosso que selecionam diretores(as) por meio de eleições e o percentual de municípios no estado de São Paulo que escolhem diretores(as) mediante concursos.

TABELA 6

AS FORMAS DE SELEÇÃO DE DIRETORES(AS) DE ESCOLAS PÚBLICAS MUNICIPAIS, POR GRANDES REGIÕES - BRASIL

\begin{tabular}{|l|c|c|c|c|c|c|}
\hline \multicolumn{1}{|c|}{ Região } & $\begin{array}{c}\text { Exclusivamente } \\
\text { indicação }\end{array}$ & $\begin{array}{c}\text { Exclusivamente } \\
\text { eleição }\end{array}$ & $\begin{array}{c}\text { Exclusivamente } \\
\text { concurso }\end{array}$ & $\begin{array}{c}\text { Exclusivamente } \\
\text { outros }\end{array}$ & $\begin{array}{c}\text { Eleição e outras } \\
\text { formas }\end{array}$ & $\begin{array}{c}\text { Indicação } \\
\text { e outras } \\
\text { formas }\end{array}$ \\
\hline Centro-Oeste & $49 \%$ & $41 \%$ & $0 \%$ & $2 \%$ & $6 \%$ & $1 \%$ \\
\hline Sul & $71 \%$ & $19 \%$ & $0 \%$ & $1 \%$ & $6 \%$ & $1 \%$ \\
\hline Norte & $81 \%$ & $12 \%$ & $0 \%$ & $1 \%$ & $4 \%$ & $2 \%$ \\
\hline Sudeste & $68 \%$ & $7 \%$ & $11 \%$ & $6 \%$ & $4 \%$ & $3 \%$ \\
\hline Nordeste & $87 \%$ & $5 \%$ & $1 \%$ & $2 \%$ & $3 \%$ & $2 \%$ \\
\hline
\end{tabular}

Fonte: Elaboração própria com base em dados da Munic (IBGE, 2014a). 
A prática de eleições na região Centro-Oeste ocorre em 74\% dos municípios do Mato Grosso, em 27,5\% dos municípios de Goiás e em 25,30\% dos municípios do Mato Grosso do Sul. Todos os estados e o Distrito Federal apresentam percentuais acima da média nacional de 12,4\% (Tabela 6; Gráfico 1).

A segunda região do País com maior porcentagem de municípios que utilizam a eleição para a seleção de diretores(as) é a Sul. No Paraná, 36\% dos municípios realizam eleições, enquanto no Rio Grande do Sul, 15\%. A menor porcentagem ocorre no estado de Santa Catarina: apenas 3,4\%. Considerando a eleição como uma das etapas do processo de seleção, a região Sul tem 25\% dos seus municípios nessa situação (Tabela 6; Gráfico 1).

A região Norte é a terceira região com maior porcentagem de municípios que realizam eleições para seleção de diretores(as), com 12\% - a média nacional. Os municípios com eleições para diretores(as) das escolas municipais da região estão mais concentrados no estado do Acre (68\%) e em Rondônia (29\%). Com uma porcentagem significativamente menor estão os estados do Pará (8,3\%), Roraima (6,7\%), Tocantins (6,5\%), Amazonas (4,8\%) e, por último, Amapá - neste, nenhum município realiza eleições para escolha de diretores(as) de escolas. Considerando os municípios que utilizam as eleições como uma das etapas da seleção, a região Norte possui 16\% deles nessa condição.

Abaixo da média nacional estão as regiões Sudeste e Nordeste, com respectivamente $7 \%$ e $5 \%$ dos municípios que realizam eleições para diretores(as) de escolas municipais. O estado do Espírito Santo tem o maior percentual de municípios da região Sudeste: 15,4\%, 2 pontos percentuais (p.p.) acima da média nacional; seguido do Rio de Janeiro, com 12\%; Minas Gerais, com 8,6\%; e São Paulo, com apenas 4\%. O Sudeste possui $11 \%$ dos seus municípios que utilizam as eleições como uma das etapas do processo de seleção de diretores(as).

Por último, a região Nordeste apresenta os menores percentuais de municípios que escolhem diretores(as) por meio de eleição: apenas 5\% do total. O estado da Bahia possui a maior porcentagem: 10,8\%; seguido de Alagoas (8,8\%), Rio Grande do Norte (7,8\%), Sergipe (4\%), Pernambuco (3,8\%), Paraíba (2,7\%), Piauí (2,7\%), Maranhão $(1,4 \%)$ e Ceará $(0,5 \%)$. A região Nordeste possui $8 \%$ dos seus municípios que utilizam as eleições como uma das etapas do processo de seleção de diretores(as), conforme Tabela 6 e Gráfico 1.

A escolha de diretores(as) das escolas municipais por meio de indicação (Tabela 6; Gráfico 1) ocorre em 74\% dos municípios do País e, em maiores proporções, nas regiões Nordeste (87\%) e Norte (81\%), seguidas das regiões Sul (71\%), Sudeste (68\%) e Centro-Oeste (49\%).

Na região Nordeste, o percentual de municípios que utilizam a indicação como forma de escolha de diretores(as) de escolas é acima da média nacional em todos os estados. O Ceará apresenta a menor porcentagem: 80,4\% dos municípios adotam a indicação. No estado da Paraíba, essa forma de escolha corresponde a 96,4\% dos municípios; seguido do Piauí, com 93,3\%, e de Sergipe, com 92\% - isso representa a quase 
universalização da indicação como forma de escolha dos municípios desses estados. Em seguida, aparecem Pernambuco (89\%), Rio Grande do Norte (88\%), Maranhão (85,7\%), Alagoas (84,3\%), Bahia (81,5\%) e Ceará $(80,4 \%)$.

Na região Norte, $81 \%$ dos municípios escolhem diretores(as) por meio de indicação. No Acre, apenas 18,2\% adotam essa forma de seleção. No Amapá, o percentual sobe para $100 \%$ dos municípios. O estado de Roraima aparece com 93,3\%, seguido de Tocantins (87\%), Pará (86\%), Amazonas (84\%) e Rondônia (61,5\%).

A quantidade de municípios que utilizam a indicação como forma de escolha de diretores(as) apresenta percentuais menores em relação à média nacional no Sul, Sudeste e Centro-Oeste. Na região Sul, 71\% dos municípios utilizam a indicação: em Santa Catarina, isso acontece em 90\% deles; no Rio Grande do Sul, o percentual reduz para 77\% dos municípios; e no Paraná, reduz ainda mais: 51\%. Na região Sudeste, o estado de Minas Gerais apresenta a maior porcentagem de municípios com indicação de diretores(as), com 82\%, seguido de Rio de Janeiro (74\%), Espírito Santo (72\%) e São Paulo (49\%).

A região com a menor porcentagem de municípios que utilizam a indicação como forma de escolha de diretores(as) é a Centro-Oeste (49\%), onde se encontram os maiores percentuais de municípios que selecionam diretores(as) por meio de eleições. No Mato Grosso, apenas 12,8\% dos municípios indicam diretores(as); no Mato Grosso do Sul, 64,6\%; em Goiás, 67\%.

O concurso como forma de escolha de diretores(as) de escolas (Tabela 6; Gráfico 1) ocorre em $4 \%$ dos municípios do território nacional, e a região Sudeste concentra a maior parte, $11 \%$ dos municípios, seguida da região Nordeste, com apenas $1 \%$.

Na região Sudeste, o maior percentual de casos ocorre no estado de São Paulo: $28,2 \%$ dos municípios utilizam o concurso como processo de seleção de diretores(as) de escola. No Norte e Nordeste, os municípios que realizam concurso como forma de escolha de diretores(as) são, em ordem, os dos estados de Rondônia (1,9\%), Amazonas $(1,6 \%)$ Sergipe $(1,3 \%)$, Ceará $(1,1 \%)$ e Alagoas (1\%).

O concurso caracteriza-se pela seleção baseada nos critérios de mérito e desempenho. Contudo, o Plano Nacional de Educação enfatiza o processo participativo em sua meta e estratégias. Assim, concurso combinado com eleições representa uma das formas possíveis de cumprimento do estabelecido na Meta 19 do PNE. Em 2014, apenas 15 municípios (0,3\%) realizavam essa combinação (Tabela 1).

Em todo o País, apenas 4\% dos municípios utilizam a eleição combinada com outras formas de seleção (Tabela 6; Gráfico 1). O Sul e o Centro-Oeste lideram as regiões nas quais a eleição é uma das etapas do processo de seleção de diretores(as) de escolas municipais: $6 \%$ dos municípios em cada região realizam eleições combinadas com outras formas de seleção. Em seguida, estão as regiões Sudeste e Norte, com 4\% dos municípios em cada região. O Nordeste aparece em último, com $3 \%$.

De outro lado, 3\% dos municípios da região Sudeste, $2 \%$ dos das regiões Norte e Nordeste e 1\% dos das regiões Sul e Centro-Oeste utilizam a indicação de diretores(as) associada a outras formas de seleção. 


\section{POPULAÇÃO DO MUNICÍPIO E FORMAS DE ESCOLHA DE DIRETORES(AS)}

Para alguns analistas, a possibilidade de participação nas decisões é relacionada ao tamanho das comunidades. Em linhas gerais, alguns autores da teoria democrática acreditam que em grupos menores as possibilidades de participação e de influência em decisões são maiores em comparação aos grandes aglomerados (Dahl, 1988; Pateman, 1980). Considerando a dimensão populacional com base em critérios de classificação dos municípios utilizados pelo IBGE, o Gráfico 2 apresenta a distribuição desses municípios a partir das formas de escolha de diretores(as) das escolas públicas municipais.

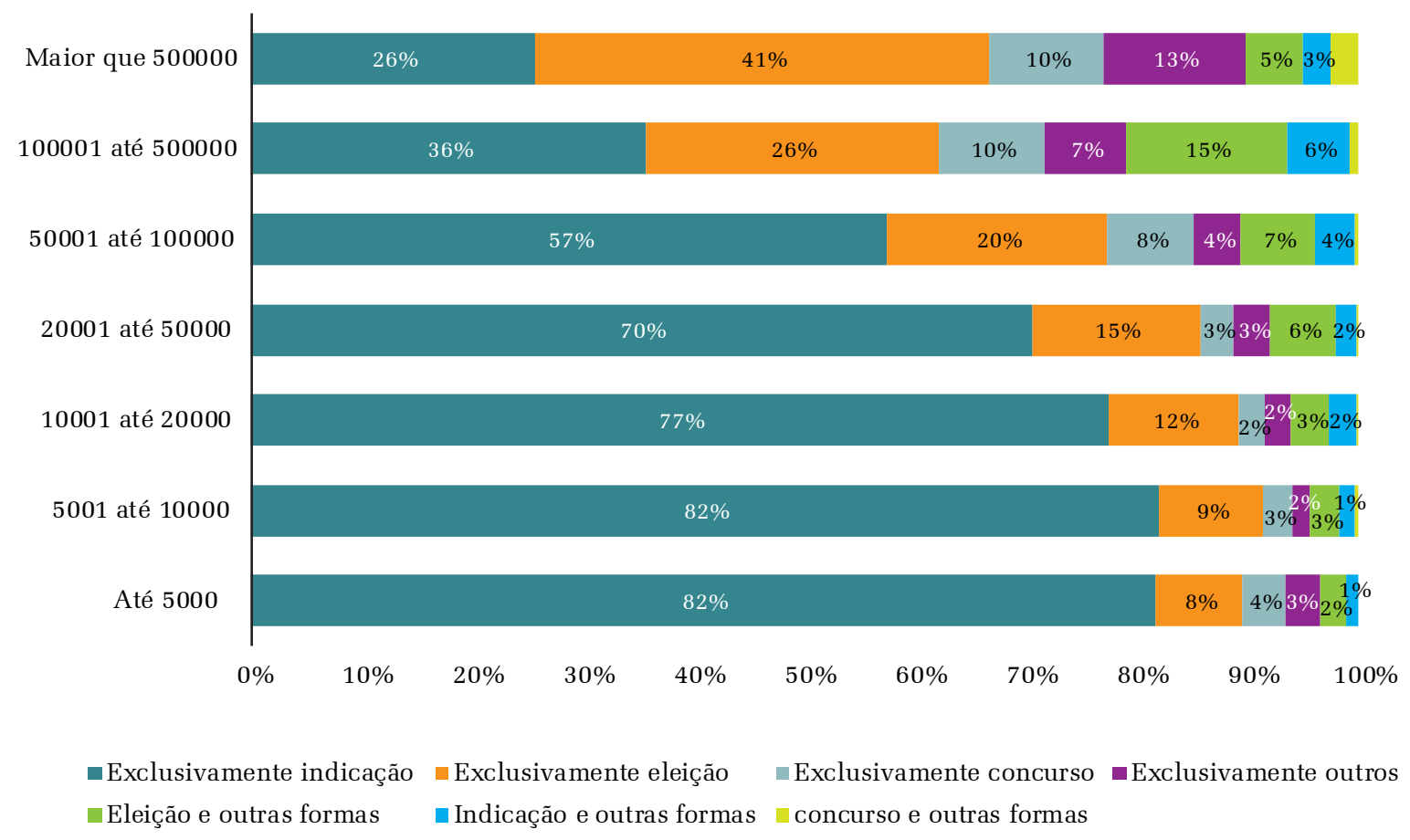

\section{GRÁFICO 2}

\section{DISTRIBUIÇÃO DOS MUNICÍPIOS SEGUNDO A FORMA DE ESCOLHA DE DIRETOR(A) E PORTE DO MUNICÍPIO - BRASIL}

Fonte: Elaboração própria com base em dados da Munic (IBGE, 2014a).

Os dados indicam que a eleição como forma de escolha de diretor(a) de escola está aparentemente relacionada com o tamanho do município. Em 41\% dos municípios com população acima de 500 mil habitantes, a forma de escolha de diretores(as) é a eleição exclusivamente. Esse percentual diminui à medida que reduz o tamanho populacional: em municípios com população entre 100 mil e 200 mil habitantes, 26\% realizam eleições para a seleção de diretores(as); já em municípios de médio porte, 
com população entre 50 mil e 100 mil habitantes, o número é $20 \%$. Na mesma porcentagem da média nacional estão os municípios menores, entre 10 e 20 mil habitantes, com $12 \%$ dos municípios realizando eleições; naqueles com população entre 20 e 50 mil habitantes, o percentual é de 15\%. Entre os municípios menores, de até 10 mil habitantes, apenas 9\% realizam eleições como forma de escolha de diretores(a).

Quando se consideram os municípios que utilizam a eleição associada a outras formas de seleção, aqueles de médio porte têm um crescimento significativamente maior em relação aos outros estratos: nesses municípios entre 100 e 500 mil habitantes, o percentual passa de $26 \%$ para $41 \%$.

O concurso como única forma de escolha também aparece em maiores porcentagens nos grandes municípios e, à medida que decresce a população, diminui o percentual daqueles que selecionam diretores(as) de escolas dessa maneira. O concurso é usado por 10\% dos municípios com população acima de 100 mil habitantes, seguidos de municípios menores, entre 50 e 100 mil habitantes: 8\% destes realizam concursos como única forma de escolha.

Enquanto os concursos e as eleições aparecem em maior percentual nos municípios de médio e grande porte e diminuem à medida que reduz o tamanho da população, a indicação de diretores(as) percorre o caminho inverso: quanto menor o tamanho do município, maior o percentual da utilização da indicação como forma de escolha de diretores(as).

Nos pequenos municípios, de até 10 mil habitantes, 82\% deles selecionam diretores(as) por meio apenas da indicação. Quando há um aumento da população, nos municípios entre 10 e 20 mil habitantes, o percentual daqueles que indicam diretores(as) reduz para 77\%, próximo da faixa dos municípios entre 20 e 50 mil habitantes, em que 70\% utilizam apenas a indicação como forma de escolha.

A partir daí os grupos seguintes e maiores apresentam percentuais significativamente menores: 57\% dos municípios com população entre 50 e 100 mil habitantes selecionam diretores(as) mediante indicação e apenas 36\% com população entre 100 e 500 mil habitantes adotam essa forma de escolha.

O menor percentual ocorre no grupo dos grandes municípios, acima de $500 \mathrm{mil}$ habitantes: apenas $26 \%$ deles utilizam a indicação como forma de seleção de diretores(as).

Assim, observa-se uma relação inversa entre o tamanho do município e o uso da indicação de diretores(as); e uma relação direta entre o tamanho do município e a escolha para esse cargo por meio de eleições.

\section{7 ÍNDICE DE DESENVOLVIMENTO HUMANO MUNICIPAL E FORMAS DE SELEÇÃO DE DIRETORES(AS)}

Em 2013, calculou-se o IDHM dos 5.565 municípios brasileiros, a partir de dados do Censo Demográfico de 2010. Assim como o IDH, o IDHM é composto por 
três dimensões: longevidade, educação e renda, adequadas aos indicadores nacionais disponíveis em bases municipais. O índice é construído a partir de uma escala que varia de 0 a 1: quanto mais próximo de 1, maior o desenvolvimento humano de um município; já a proximidade com o 0 indica baixo desenvolvimento.

Os municípios foram classificados a partir de cinco grupos no Atlas do Desenvolvimento Humano no Brasil 2013: municípios com IDHM até 0,500 foram classificados como de Muito Baixo IDHM; municípios com IDHM entre 0,500 e 0,599 foram classificados como de Baixo IDHM; municípios com IDHM entre 0,600 e 0,699 foram classificados como de Médio IDHM; municípios com IDHM entre 0,700 e 0,799 foram classificados como de Alto IDHM; municípios com IDHM acima de 0,800 foram classificados como de Muito Alto IDHM (Figura 1).

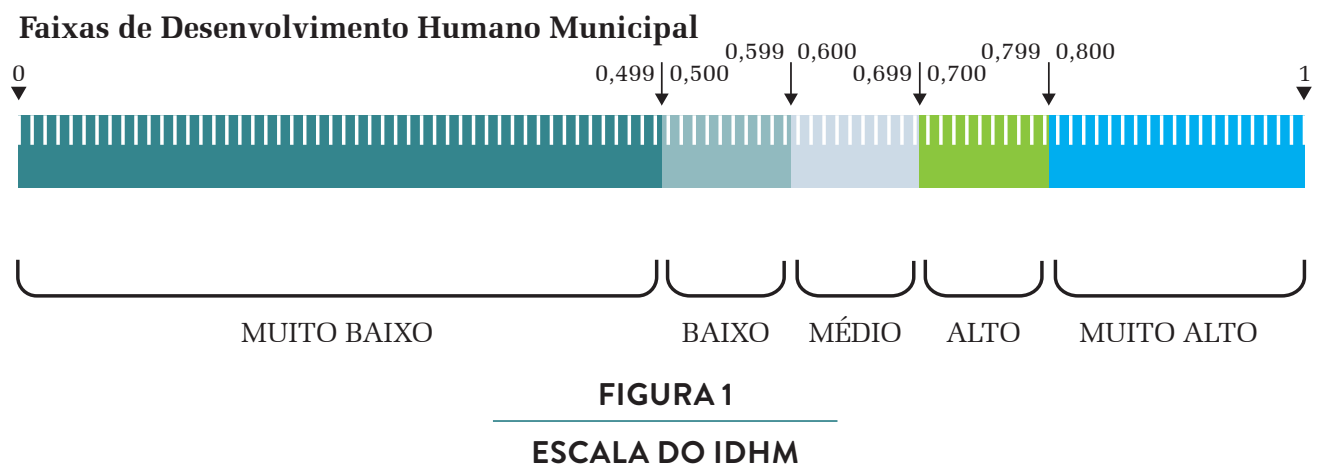

Fonte: Pnud (2013).

TABELA 7

DISTRIBUIÇÃO DOS MUNICÍPIOS POR FAIXA DE IDHM - BRASIL

\begin{tabular}{|c|c|c|c|}
\hline Categoria & $\mathbf{N}$ & $\%$ & $\%$ acumulado \\
\hline Muito baixo & 35 & 0,6 & 0,6 \\
\hline Baixo & 1364 & 24,5 & 25,1 \\
\hline Médio & 2233 & 40,1 & 65,3 \\
\hline Alto & 1889 & 33,9 & 99,2 \\
\hline Muito alto & 44 & 0,8 & 100 \\
\hline Total & $5565^{1}$ & 100 & \\
\hline Casos faltantes & 5 & & \\
\hline Total & 5570 & & \\
\hline
\end{tabular}


Para os fins deste estudo, o IDHM tem a vantagem de constituir-se como indicador do bem-estar das pessoas, "[...] entendido como a ampliação do escopo das escolhas e da capacidade e da liberdade de escolher" (Pnud, 2013, p. 23). Nesse sentido, a possibilidade de participar das decisões da escola é uma dessas opções de escolha, uma dessas liberdades nem sempre usufruídas por aqueles que têm esse direito, seja por desconhecimento, seja por falta de condições para usufruí-lo. Os números revelam uma relação entre o alto IDHM e um maior percentual de municípios que realizam eleições como forma de escolha de diretores(as) de escolas municipais (Tabela 8).

TABELA 8

TIPO DE PROVIMENTO DO CARGO POR FAIXA DE IDHM - BRASIL

\begin{tabular}{|l|c|c|c|c|c|c|}
\hline Faixas IDHM & $\begin{array}{c}\text { Exclusivamente } \\
\text { indicação }\end{array}$ & $\begin{array}{c}\text { Exclusivamente } \\
\text { eleição }\end{array}$ & $\begin{array}{c}\text { Exclusivamente } \\
\text { concurso }\end{array}$ & $\begin{array}{c}\text { Exclusivamente } \\
\text { outros }\end{array}$ & $\begin{array}{c}\text { Eleição e outras } \\
\text { formas }\end{array}$ & $\begin{array}{c}\text { Indicação } \\
\text { e outras } \\
\text { formas }\end{array}$ \\
\hline Muito Baixo & $91 \%$ & $6 \%$ & $0 \%$ & $0 \%$ & $3 \%$ \\
\hline Baixo & $89 \%$ & $5 \%$ & $0 \%$ & $2 \%$ & $2 \%$ \\
\hline Médio & $78 \%$ & $13 \%$ & $1 \%$ & $3 \%$ & $3 \%$ & $2 \%$ \\
\hline Alto & $60 \%$ & $18 \%$ & $8 \%$ & $4 \%$ & $6 \%$ & $3 \%$ \\
\hline Muito Alto & $36 \%$ & $16 \%$ & $27 \%$ & $9 \%$ & $5 \%$ \\
\hline
\end{tabular}

Fonte: Elaboração própria com base em dados da Munic (IBGE, 2014a) e do IDHM (Pnud, 2013).

A distribuição dos municípios a partir das faixas de IDHM estabelecidas revela percentuais maiores de práticas eleitorais naqueles classificados nas faixas de Alto e Muito Alto IDHM (Tabela 8).

Entre os municípios com Alto IDHM, 18\% realizam eleições para a seleção de diretores(as) das escolas municipais, seguidos daqueles classificados na faixa de Muito Alto IDHM, com 16\%. No caso dos municípios com Baixo IDHM, apenas 5\% realizam eleições; entre aqueles com Muito Baixo IDHM, são 6\%. Já entre os municípios classificados como de Médio IDHM, 13\% realizam eleições nas escolas, 5 p.p. menos em relação aos municípios com Alto IDHM (18\%).

Entre os casos de municípios que combinam eleições e outras formas de seleção não descritas, quanto maior a faixa de IDHM, maiores são os percentuais daqueles que praticam eleições para escolha de diretores(as) de escolas municipais.

Enquanto os maiores percentuais de municípios com eleições acontecem entre os classificados com Alto e Muito Alto IDHM, a indicação como forma exclusiva de seleção de diretores(as) predomina entre os municípios classificados com Muito Baixo e Baixo IDHM.

Entre os municípios com Muito Baixo IDHM, 91\% indicam diretores(as); esse percentual cai para 89\% entre aqueles de Baixo IDHM. Entre os municípios de Médio IDHM, o percentual dos que indicam diretores(as) é de $78 \%$ e esse número recua para $60 \%$ dos municípios de Alto IDHM e para apenas 36\% dos classificados com 
Muito Alto IDHM. Mais uma vez, a maior diferença acontece entre os municípios de Muito Baixo e Baixo IDHM e aqueles acima de Médio.

Ao considerar os municípios que selecionam diretores(as) por meio de concurso, observa-se concentração entre os classificados com Muito Alto IDHM: 27\%. Na sequência, estão os municípios com Alto IDHM: 8\%. Entre aqueles de Médio IDHM, apenas 1\% realiza concursos. Na faixa de Muito Baixo IDHM, não existem casos e, na de Baixo IDHM, o percentual é inferior a $1 \%$.

A trajetória inversa entre desenvolvimento humano e forma de escolha de diretores(as) também ocorre quando se observam os municípios que realizam outras formas de seleção de diretores(as) de escolas não previstas no questionário da Munic: quanto maior a faixa de desenvolvimento social, maior a porcentagem de municípios que praticam formas diferentes de seleção de diretores(as), não inclusas no questionário desta pesquisa.

Em municípios de Muito Alto IDHM, 9\% realizam outras formas de seleção de diretores(as) de escolas; seguidos daqueles classificados com Alto IDHM: 8\%. Municípios de Muito Baixo IDHM não possuem casos, enquanto os de Baixo e Médio IDHM possuem, respectivamente, $2 \%$ e $3 \%$ de municípios que adotam outras formas de escolha de diretores(as) municipais.

A relação entre altos índices de IDHM e prática de eleições e, inversamente, a relação entre baixos índices de IDHM e prática de indicação como forma de escolha de diretores(as) das escolas públicas municipais devem ser complementadas com a análise dos casos de municípios que selecionam diretores(as) por meio de concurso ou de outras formas não previstas no questionário. Os casos ocorrem com maior frequência em municípios de Alto e Muito Alto IDHM, sugerindo uma relação entre o experimento de outras formas de escolha de diretores(as) e o nível de desenvolvimento humano do município, o que também acontece no caso do uso do concurso.

\section{CONSELHO MUNICIPAL DE EDUCAÇÃO E FORMAS DE ESCOLHA DE DIRETORES(AS) MUNICIPAIS}

A participação política é vista, em parte da teoria política, como mais fácil e efetiva em espaços com tamanho reduzido de habitantes. Para Avritzer e Ramos (2016), essas avaliações muitas vezes desconsideram as condições institucionais criadas pelo Estado e que possibilitam a participação em realidades mais complexas. As chamadas instituições participativas, como conselhos, podem alterar os níveis de participação, sua efetividade, e, nesse sentido, têm sido objeto de diversos estudos sobre democracia e participação. Assim, os CMEs podem ser considerados instituições participativas criadas pelo Estado. 


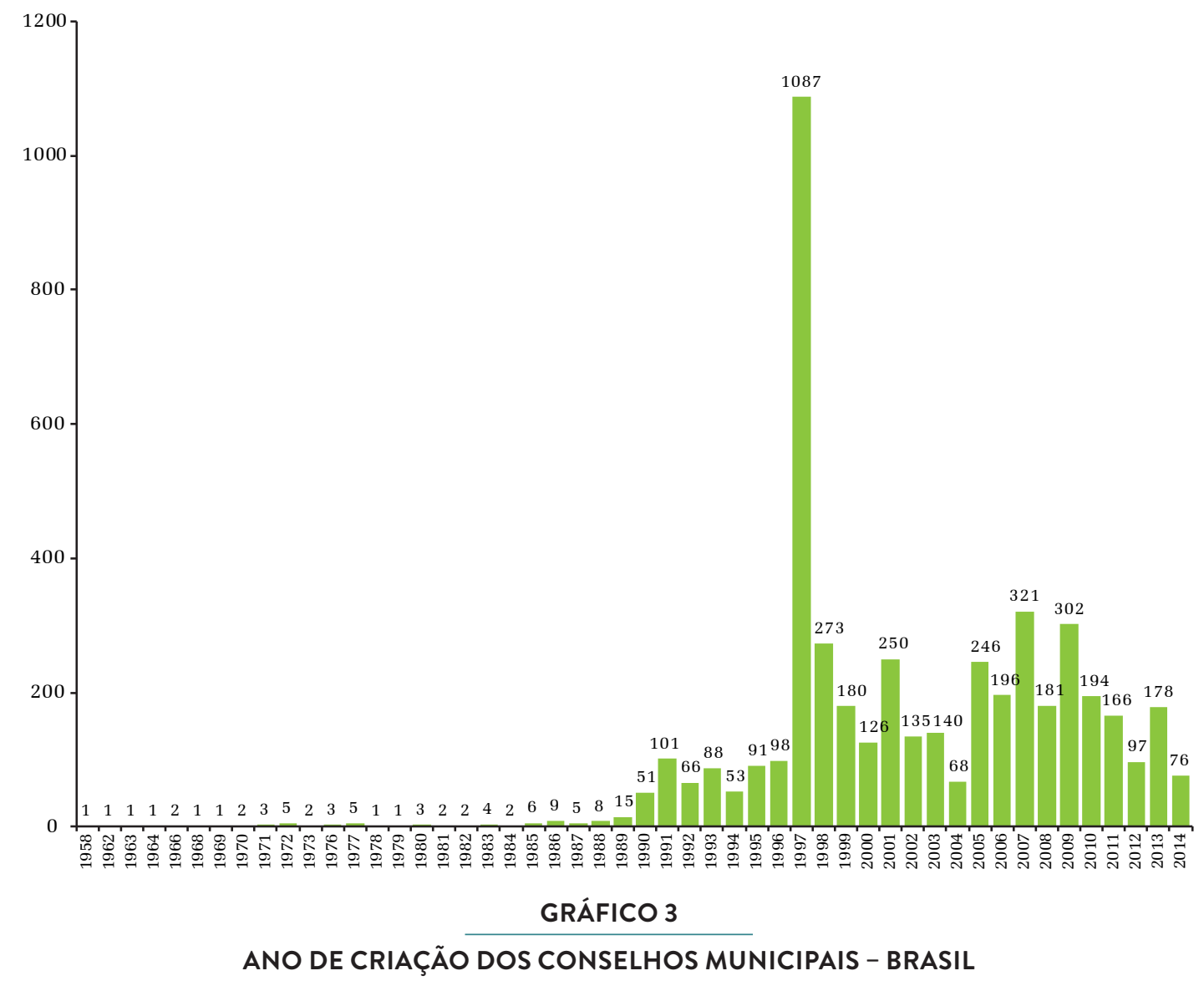

Fonte: Elaboração própria com base em dados da Munic (IBGE, 2014a).

A maior parte dos CMEs (87\%) foi criada entre 1996 e 2014. Até 1996, ano da aprovação da LDB, apenas 13\% dos municípios possuíam conselho; após a aprovação, em 1997, foram criados 1.087, 19,5\% do total dos conselhos existentes atualmente, o que denota uma experiência ainda relativamente recente na estruturação institucional dos sistemas de ensino. Foram encontrados 4.858 municípios com conselho municipal de educação em funcionamento, 87,2\% do total dos municípios da Federação (Gráfico 3).

Quando se analisa a quantidade de reuniões dos conselhos ao longo do ano, observam-se algumas tendências. A primeira delas refere-se à média de reuniões dos CMEs associada à forma de escolha de diretores(as) das escolas municipais (Gráfico 4): os CMEs dos municípios que utilizam a indicação como forma de escolha de diretores(as) realizam, em média, 7,8 reuniões anuais; os CMEs dos municípios que escolhem diretores(as) por meio de eleições realizam, em média, 10,38 reuniões por ano, a maior média entre as diferentes formas de escolha de diretores(as) das escolas municipais; os CMEs dos municípios que utilizam as eleições como apenas uma etapa do processo de escolha realizam, em média, 8,28 reuniões anuais; seguidos dos CMEs dos municí- 
pios que utilizam indicação e eleição simultaneamente, em frequência média de 8,09 reuniões anuais (Tabela 9).

Os municípios que selecionam diretores(as) por meio de concurso realizam em média 7,98 reuniões anuais, média de reuniões próxima daqueles CMEs localizados em municípios em que se escolhe diretor(a) por meio de indicação. Entre CMEs que escolhem diretores(as) por formas não previstas no questionário, a média de reuniões é de 5,82.

TABELA 9

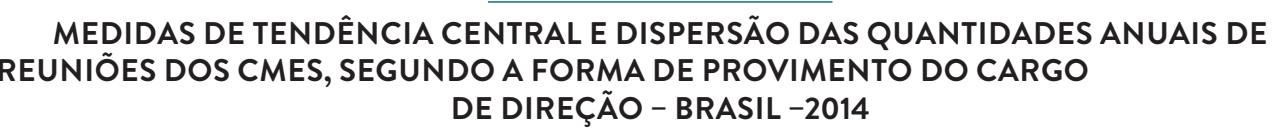

\begin{tabular}{l|c|c|c|c|c} 
& Média & Mediana & $\begin{array}{c}\text { Desvio } \\
\text { Padrão }\end{array}$ & Mínimo & Máximo \\
\hline Indicação & 7,80 & 6,00 & 8,271 & 0 & 88 \\
\hline Eleição & 10,34 & 8,00 & 10,790 & 0 & 104 \\
\hline Concurso & 7,98 & 6,00 & 8,924 & 0 & 120 \\
\hline Exclusivamente outros & 5,82 & 4,00 & 5,543 & 0 & 60 \\
\hline Misto (indicação e eleição) & 8,09 & 6,00 & 7,170 & 0 & 96 \\
\hline Misto (indicação e outros) & 5,84 & 4,00 & 9,503 & 0 & 101 \\
\hline Misto (eleição e outros) & 8,28 & 8,00 & 6,975 & 0 & 48 \\
\hline
\end{tabular}

Fonte: Elaboração própria com base em dados da Munic (IBGE, 2014a).

O Gráfico 4 apresenta a distribuição da quantidade de reuniões do CME por municípios. Os dados mostram que 265 municípios não realizaram reuniões anuais; 1.660 fizeram entre 1 e 4 reuniões; 2.519, entre 5 e 12 reuniões; 292, entre 13 e 24 reuniões; 122 municípios, mais de 24 vezes ao ano; 9 municípios, mais de 90 vezes ao ano.

Em termos percentuais, 16,9\% dos municípios com CME realizaram reuniões mensais; 14,2\%, bimestrais; 12,5\%, trimestrais; e 9,8\%, semestrais. Além disso, 5,5\% dos conselhos não se reuniram nos últimos doze meses da pesquisa. Essas frequências de reuniões dos CMEs representam 53,4\% das respostas à questão; o restante está distribuído em percentuais menores.

Considerando a frequência de reuniões dos CMEs como um indicativo de maior participação na gestão da educação, observa-se que as maiores frequências de reuniões anuais ocorrem nos municípios que selecionam diretores(as) por meio de eleições. Enquanto no grupo dos CMEs que realizam até duas reuniões anuais, 80\% funcionam em municípios que elegem diretores(as) por meio de indicação. De maneira inversa, no grupo dos CMEs que realizam entre 18 e 24 reuniões anuais, 35\% estão localizados em municípios que têm a consulta à comunidade como uma das etapas de escolha de diretores(as) das escolas municipais. 


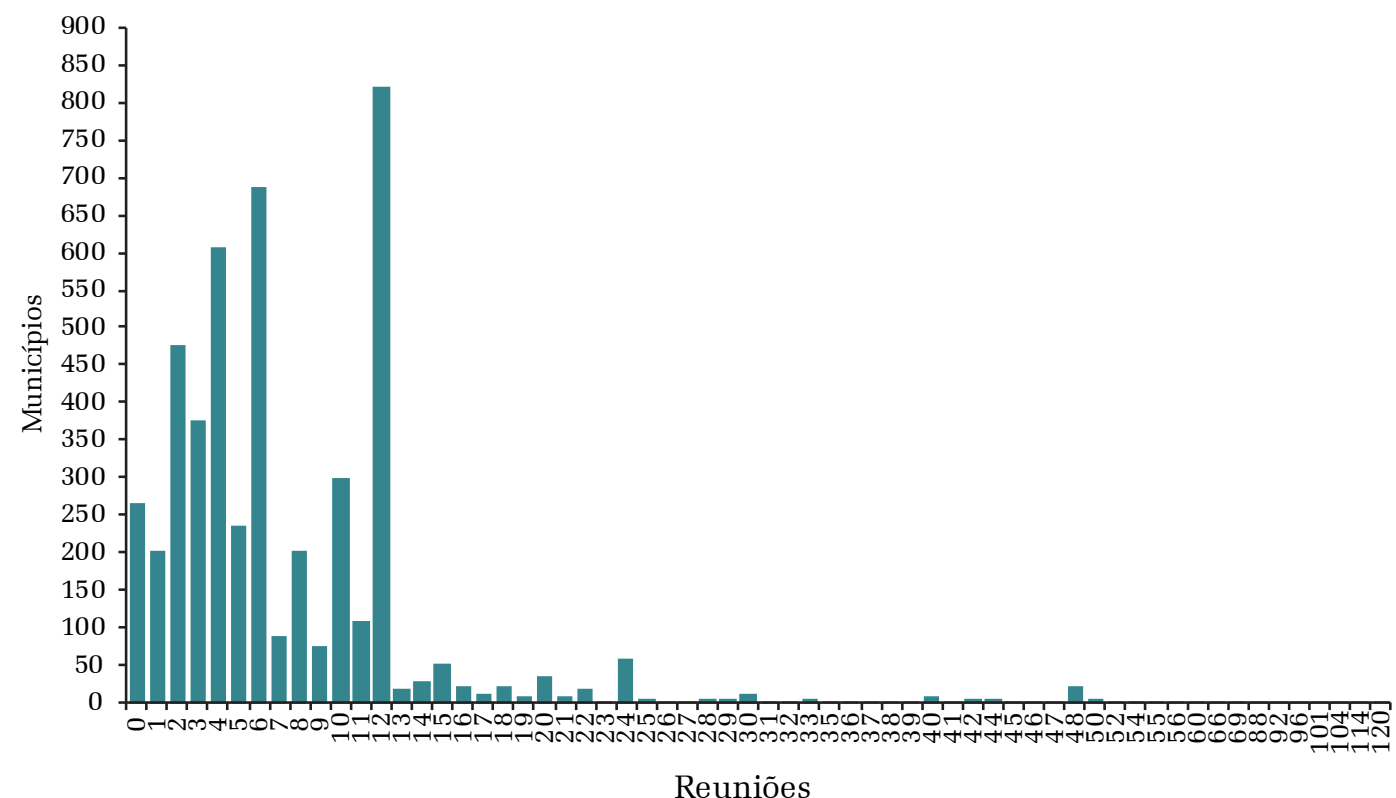

GRÁFICO 4 QUANTIDADE DE REUNIÕES DO CME, POR MUNICÍPIOS - BRASIL

Fonte: Elaboração própria com base em dados da Munic (IBGE, 2014a).

\section{ANÁLISE DAS DIFERENÇAS NAS CHANCES DE PROVIMENTO}

As análises anteriores permitiram uma compreensão acerca das formas de seleção de diretores(as) das escolas municipais, bem como uma caracterização das formas pelas quais os tipos de provimento se distribuem nos estados, regiões, pelo tamanho do município e pelo IDHM. Com a finalidade de compreender com mais detalhes as características que se associam as eleições nas escolas como forma de provimento dos cargos na rede municipal, introduziu-se uma análise das razões de chance, por meio de modelo de regressão logística, para que um município adote a eleição.

Segundo Figueiredo Filho et al. (2015), a regressão logística binomial permite estimar o efeito de diferentes variáveis independentes sobre a probabilidade de pertencimento a um determinado grupo. Para isso, foi desenvolvido um modelo de regressão que ajuda a entender o peso diferenciado de cada dimensão analisada descritivamente para a compreensão do tipo de provimento adotado (Quadro 2). 


\section{QUADRO 2}

\section{REPRESENTAÇÃO ESQUEMÁTICA DOS MODELOS}

\begin{tabular}{|c|c|}
\hline Variável Dependente (VD) & Variáveis Independentes (VI) \\
\hline $\begin{array}{l}\text { Eleição (modelo 1) } \\
(0=\text { não; } 1=\operatorname{sim})\end{array}$ & $\begin{array}{l}\text { - Faixa de tamanho do município ( } 1 \text { a } 7 \text { ) } \\
\text { - Faixa do IDHM ( } 1 \text { a } 5 \text { ) } \\
\text { - Tipo de provimento na rede estadual em que o } \\
\text { município se localiza } \\
\text { - Quantidade de reuniões do conselho municipal de } \\
\text { educação }\end{array}$ \\
\hline
\end{tabular}

Fonte: Elaboração própria.

Foram avaliadas as chances de o município adotar eleição como forma exclusiva de provimento. O modelo apresentou um Pseudo $\mathrm{R}^{2}$ de 0,127 , o que permite afirmar que as quatro variáveis independentes incluídas no modelo 1 explicam 12,7\% da variação da variável dependente (VD). A análise dos coeficientes do modelo 1 mostrou que todos foram estatisticamente significativos ( $p$-valor <0,05). A variável com o menor coeficiente foi a quantidade de reuniões do conselho municipal de educação feitas por ano. É possível afirmar que a realização de uma reunião ou mais por ano amplia em $0,1 \%(\operatorname{Exp} B=1,011)$ as chances de que o município adote eleições como forma de escolha de diretores(as) de escolas (Tabelas 10).

O aumento de uma faixa do tamanho do município amplia em $35,3 \%$ as chances de ocorrer eleições para diretores(as) no município (Tabela 10). Os dados relacionados ao IDHM revelaram que os municípios com maior índice apresentam maiores chances de adotar eleições. O aumento em uma faixa do IDHM representa uma ampliação de 83,6\% nas chances de o município adotar eleições em suas escolas (ExpB de 1,836).

Por fim, a variável com maior coeficiente no modelo 1 foi a relativa ao fato de a rede estadual adotar ou não eleições para seleção de diretores(as): municípios localizados em estados que realizam eleições para diretores(as) da rede estadual apresentam 113\% mais chances de adotar essa forma de escolha, quando comparados aos municípios localizados em estados que não utilizam eleições.

TABELA 10

COEFICIENTES DO MODELO

\begin{tabular}{|l|c|c|c|c|c|c|c|}
\hline & \multicolumn{7}{|c|}{$95 \%$ C.I. for ExpB } \\
\hline Modelo 1 - VD Eleição & B & S.E. & df & Sig. & ExpB & Lower & Upper \\
\hline Tamanho do município & 0,302 & 0,029 & 1 & 0,00 & 1,353 & 1,279 & 1,431 \\
\hline Faixas de IDHM & 0,608 & 0,058 & 1 & 0,00 & 1,836 & 1,638 & 2,058 \\
\hline Eleição no estado & 0,756 & 0,089 & 1 & 0,00 & 2,13 & 1,791 & 2,534 \\
\hline Quantidade de reuniões do conselho & 0,011 & 0,004 & 1 & 0,01 & 1,011 & 1,003 & 1,02 \\
\hline Constant & $-5,011$ & 0,224 & 1 & 0,00 & 0,007 & & \\
\hline
\end{tabular}

Fonte: Elaboração própria com base em dados Munic (IBGE, 2014a). 
Assim, observa-se que a variável com o maior ExpB é a forma de escolha de diretores(as) do estado ao qual o município pertence. A mudança de faixa IDHM tem uma forte influência no modelo da eleição, assim como o tamanho do município.

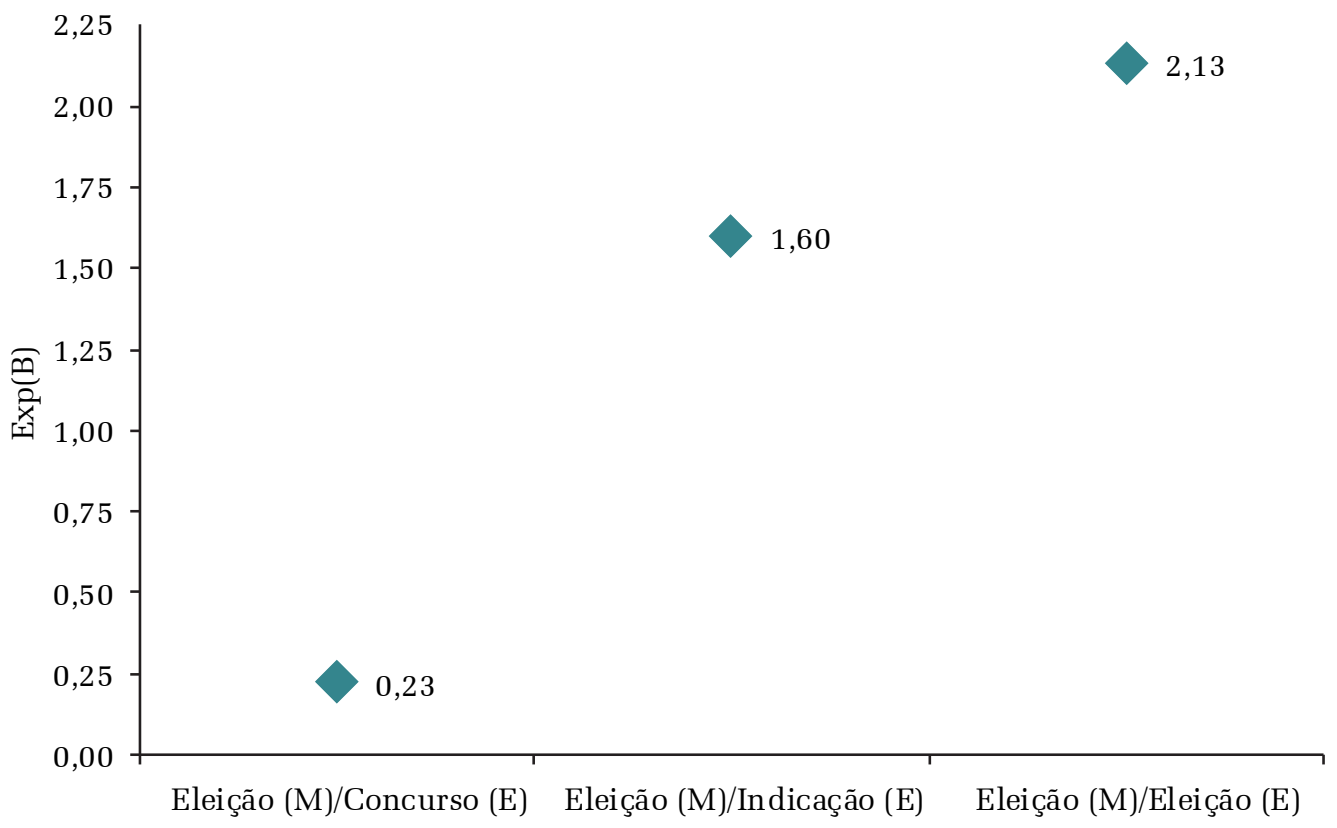

GRÁFICO 5

\section{COMPARAÇÃO DOS EXPB COM BASE EM DIFERENTES SITUAÇÕES DE PROVIMENTO DO CARGO DE DIRETOR(A) DE ESCOLAS NOS ESTADOS - BRASIL}

Fonte: Elaboração própria com base em dados da Munic (IBGE, 2014a).

Considerou-se inicialmente a forma de escolha de cada estado da Federação ao qual o município pertencia. Para fins de comparação, construíram-se outros três modelos, mantendo-se como variável dependente as chances de o município adotar eleição e, nas variáveis independentes, alterou-se a forma como o estado escolhia diretores(as), substituindo a forma de seleção original de cada estado por uma das três possíveis (Gráfico 5).

No caso de os estados utilizarem o concurso como forma de escolha de diretores(as) estaduais, as chances de o município adotar eleição são reduzidas em 77\%; já entre os estados que escolhem diretores(as) mediante indicação, as chances de os municípios realizarem eleição são de 60\%; e nos estados em que a eleição é a forma de escolha de diretores(as) estaduais, as chances de os municípios também adotarem as eleições são de $113 \%$.

Observa-se que municípios localizados em estados que adotam concurso como forma de escolha são os que possuem as mais reduzidas chances de selecionar diretores(as) por meio de eleições, enquanto municípios localizados em estados que 
adotam a eleição na escolha de diretores(as) possuem as maiores chances de também realizá-la (Gráfico 5).

\section{CONSIDERAÇÕES FINAIS}

Uma das principais dificuldades apontadas ao monitoramento da Meta 19 do Plano Nacional da Educação é encontrar indicadores capazes de traduzir a existência de uma gestão democrática nas escolas brasileiras, coletados de maneira contínua e consistente. A essa dificuldade adiciona-se o intenso debate em torno do conceito de gestão democrática.

A análise dos resultados sobre as formas de provimento de diretores(as), a partir das variáveis selecionadas, revela que os municípios com eleição, concurso ou outras formas não previstas no questionário possuem diversas características comuns.

A escolha de diretores(as) das escolas públicas municipais por meio de eleições concentra-se em municípios de médio (26\%) e grande porte (41\%); classificados com Médio IDHM (13\%), Alto IDHM (18\%) e Muito Alto IDHM (16\%); localizados nas regiões Centro-Oeste (41\%), Sul (19\%) e Norte (12\%).

No estado do Mato Grosso, 73\% dos municípios praticam eleições, a maior taxa do País, seguida pela do Acre: 68,2\%. O Paraná é o terceiro estado do País, com $36,3 \%$ dos municípios que realizam eleições para diretores(as) de escolas; seguido de Rondônia (28,8\%), Goiás (27,6\%) e Mato Grosso do Sul (25,3\%). Esses seis estados apresentam o dobro do percentual nacional de municípios com eleições. Importante observar que nesses estados a rede estadual já selecionava diretores(as) mediante eleições: o Mato Grosso desde 1990, com a aprovação da Lei $n^{0}$ 5.604; e o Acre desde 2003, com a aprovação da Lei $n^{0} 1.513$.

Embora Centro-Oeste e Sul concentrem mais de 70\% dos municípios com eleições como forma escolha de diretores(as) de escolas, essas regiões possuem quantidade significativamente menor de municípios em relação a outras regiões, o que poderia distorcer algumas possíveis conclusões.

Quando se observa o tamanho do município, em linhas gerais, as eleições acontecem com mais frequência naqueles com população acima de 100 mil habitantes. Na faixa dos municípios entre 100 e 500 mil habitantes, 26\% realizam eleições e 15\% o fazem em combinação com outras formas de seleção. Somam-se, pois, 41\% dos municípios dessa faixa que praticam eleições, o que revela uma maior variedade de experiências utilizando essa forma de seleção.

Por outro lado, os municípios com população acima de 500 mil habitantes têm consolidada a forma de eleição como seleção de diretores(as), com 41\%; e são poucos os casos de combinações entre eleições e outras formas: apenas $5 \%$.

Além da dimensão populacional, o alto grau de desenvolvimento humano é outra característica desses municípios: entre os de Muito Alto IDHM, 25\% realizam 
eleições; seguido dos municípios com Alto IDHM, dos quais 22\% adotam essa forma de escolha de diretores(as) de escolas municipais.

Essas características de desenvolvimento social e dimensão populacional também estão presentes nos municípios que realizam concursos: são de grande e médio porte, com Alto IDHM e concentrados na região Sudeste, especialmente no estado de São Paulo, os municípios que mais realizam concursos para provimento do cargo de diretores(as).

Entre municípios com população acima de 100 mil habitantes, 10\% realizam concursos como forma de escolha de diretores(as) das escolas públicas municipais. Entre os municípios localizados na faixa mais alta de IDHM, 27\% realizam concurso; seguidos bem de longe por aqueles classificados na faixa de Alto IDHM: 8\%.

A principal diferença entre as três principais formas de seleção de diretores(as) das escolas das redes municipais de ensino ocorre quando se observa a localização dos municípios: se as eleições se concentram no Centro-Oeste e no Sul, os concursos e as outras formas não previstas no questionário estão concentrados na região Sudeste.

Os modelos permitiram avaliar o peso diferenciado de cada dimensão analisada para a compreensão do tipo de provimento adotado. Nesse sentido, reforça-se a importância de cada rede estadual com relação à forma de provimento dos seus municípios, com os maiores coeficientes entre as variáveis independentes.

Embora a efetivação da Meta 19 do Plano Nacional de Educação não envolva o desembolso de grandes quantidades de recursos financeiros para sua execução, os desafios ao seu cumprimento se juntam aos das outras metas do PNE cujo deficit se concentra nas regiões mais pobres do País.

A utilização das eleições como forma de provimento para o cargo de diretor(a) das escolas públicas depara-se com desafios de outra natureza, como os dados relacionados ao tamanho do município ou ao IDHM revelaram, mas também com desafios referentes ao interesse político na efetivação dessas metas.

Considerando a aprovação dos planos estaduais de educação e os compromissos assumidos com relação à gestão democrática, a partir de 2018, são possíveis grandes progressos no cumprimento dessa meta. Como observado, os estados da Federação que escolhem diretores(as) por meio das eleições há mais tempo são os que apresentam os maiores percentuais de municípios que adotam essa forma de seleção.

Os resultados apresentados indicam que a política pública de incentivo a realização de eleições como forma de escolha de diretores(as) das escolas públicas encontra suas limitações no contexto socioeconômico. Em alguns casos, é necessário mais do que a legislação promotora da participação. Os municípios que se caracterizam por selecionar diretores(as) por meio de indicação possuem indicadores socioeconômicos mais baixos em relação ao IDHM e ao tamanho populacional, revelando que outros fatores ainda precisam ser superados para que a eleição de diretores(as) possa se tornar uma política efetivamente implementada no Brasil. 


\section{REFERÊNCIAS}

ALBUQUERQUE, A. E. M. O princípio da gestão democrática na educação pública. Brasília: Líber Livro; Faculdade de Educação/UNB, 2012. (Coleção Políticas Públicas de Educação).

AVRITZER, L. Sociedade civil e Estado no Brasil: da autonomia à interdependência política. Opinião Pública, Campinas, v. 18, n. 2, p. 383-398, nov. 2012.

AVRITZER, L.; RAMOS, A. Democracia, escala y participación. Reflexiones desde las instituiciones participativas brasilenhas. Revista Internacional de Sociologia, [Madrid], v. 74, n. 3, 2016.

BRASIL. Constituição (1988). Constituição da República Federativa do Brasil. Diário Oficial da União, Brasília, DF, 5 out. 1988. Seção 1. p. 1.

BRASIL. Lei $\mathrm{n}^{\mathrm{O}}$ 10.172, de 9 de janeiro de 2001. Aprova o Plano Nacional de Educação e dá outras providências. Diário Oficial da União, Brasília, DF, 10 jan. 2001. Seção 1, p. 1.

BRASIL. Lei $\mathrm{n}^{\mathrm{O}}$ 13.005, de 25 de junho de 2014. Aprova o Plano Nacional de Educação - PNE e dá outras providências. Diário Oficial da União, Brasília, DF, 26 jun. 2014. Seção 1, p. 1. Edição Extra.

BRASIL. Lei $\mathrm{n}^{\circ}$ 7.398, de 4 de novembro de 1985. Dispõe sobre a organização de entidades representativas dos estudantes de $1^{\circ}$ e $2^{\circ}$ graus e dá outras providências. Diário Oficial da União, Brasília, DF, 5 nov. 1985. Seção 1, p. 16113.

BRASIL. Lei no 9.394, de 20 de dezembro de 1996. Estabelece as diretrizes e bases da educação nacional. Diário Oficial da União, Brasília, DF, 23 dez. 1996. Seção 1, p. 27833.

CALDEIRA, T. Democracy and violence in Brazil. Comparatives Studies in Society and History, [S.l.], v. 41, n. 4, p. 691-729, Oct. 1999.

DAHL, R. On Democracy. New Haven: Yale University Press, 1988.

DALBERIO, M. C. B. Políticas educacionais e a gestão democrática da escola pública de qualidade. São Paulo: Paulus, 2009.

DOURADO, L. F. Gestão da educação escolar. Brasília: Universidade de Brasília, 2006. 
DOURADO, L. F. A escolha de dirigentes escolares: políticas e gestão da educação no Brasil. In: FERREIRA, N. S. C. (Org.). Gestão democrática da educação. São Paulo: Cortez, 2011. p. 95-117.

FIGUEIREDO FILHO, D. et al. Regressão Logística em Ciência Política. [Recife: UFPE], 2015. Mimeografado.

GOMES, A. V. Plano Nacional de Educação: construção e perspectivas. Brasília: Câmara dos Deputados, 2015.

GRACINDO, R. V. Gestão democrática nos sistemas e na escola. Brasília: Universidade de Brasília, 2007.

GRACINDO, R. V.; BORDIGNON, G. V. Gestão da educação: o município e a escola. In: FERREIRA, N. S. C.; AGUIAR, M. A. da S.; FERREIRA, N. S. C. (Org.). Gestão da educação: impasses, perspectivas e compromissos. São Paulo: Cortez, 2004. p. 147-162.

GUTIERREZ, G. L.; CATANI, A. Participação e gestão escolar: conceitos e potencialidades. In: FERREIRA, N. S. C. (Org.). Gestão democrática da educação. São Paulo: Cortez, 1998. p. 59-65.

HOLSTON, J. Urban Citizenship and Globalization. In: SCOTT, A. J. (Ed.). Global City-Regions: trends, theory policy. Oxford: University Press, 2001. Cap. 17.

INSTITUTO BRASILEIRO DE GEOGRAFIA E ESTATÍSTICA (IBGE). Pesquisa de Informações Básicas Municipais (Munic). Rio de Janeiro: IBGE, 2014a.

INSTITUTO BRASILEIRO DE GEOGRAFIA E ESTATÍSTICA (IBGE). Pesquisa de Informações Básicas Estaduais (Estadic). Rio de Janeiro: IBGE, 2014b.

LIBÂNEO, J. C. Organização e gestão da escola: teoria e prática. São Paulo: Editora Alternativa, 2008.

LIMA, L. C. A gestão democrática das escolas: do autogoverno à ascensão de uma pós-democracia gestacionária? Educação e Sociedade, Campinas, v. 35, n. 129, p. 1063-1083, out./dez. 2014.

MADISON, J.; JAY, J. O Federalista. São Paulo: Abril Cultural, 1985.

MENDONÇA, E. A gestão democrática nos sistemas de ensino brasileiros: a intenção e o gesto. In: REUNIÃO ANUAL DA ANPED, 23., 2000, Caxambu. Anais... Caxambu: Anped, 2000. 
MENDONÇA, E. Estado patrimonial e a gestão democrática do ensino público no Brasil. Educação \& Sociedade, Campinas, ano 22, n. 75, p. 84-108, ago. 2001.

OLIVEIRA. J. F.; MORAES, K. N. de; DOURADO, L. F. Gestão escolar democrática: definições, princípios e mecanismos de implementação. Brasília: MEC, 2008. Disponível em: <http://escoladegestores.mec.gov.br/site/4-sala_politica_gestao_ escolar/pdf/texto2_1.pdf>. Acesso em: 15 out. 2018.

PARO, V. H. Gestão da escola pública: a participação da comunidade. Revista Brasileira de Estudos Pedagógicos, Brasília, v. 73, n. 74, p. 255-290, maio/ago. 1992.

PATEMAN, C. Participation and Democratic Theory. Cambridge: Cambridge University Press, 1980.

PROGRAMA DAS NAÇÕES UNIDAS PARA O DESENVOLVIMENTO (Pnud). $O$ Índice de Desenvolvimento Humano Municipal Brasileiro. Brasília: Pnud; Ipea; FJP, 2013. (Atlas do Desenvolvimento Humano no Brasil 2013).

SCHLESENER, A. H. Gestão democrática da educação e formação dos Conselhos Escolares. In: FERREIRA, N. S. C. (Org.). Políticas públicas e gestão da educação: polêmicas, fundamentos e análises. Brasília: Líber Livro, 2006. p. 177-189.

TORRES, A.; GRASKE, L. M. Diretores de escola: o desacerto com a democracia. Em Aberto, Brasília, v. 17, n. 72, p. 60-70, fev./jun. 2000. 